\title{
Rounded Square Ring Resonator Based Add Drop Filter for Wdm Applications Using Two Dimensional Photonic Crystals
}

\section{Massoudi Radhouene}

Université de Tunis El Manar,National Engineering school of Tunis Communication Systems

V R Balaji ( $\sim$ photonics.material@gmail.com)

VIT Chennai campus

\section{Monia Najjar}

University of Tunis El manar,Higher institute of computer, Tunisia

\section{S Robinson}

Mount zion college of engineering and Technology

Vijay Janyani

Malaviya National Institute of Technology

\section{Murugan}

Valliammai Engineering College

\section{Research Article}

Keywords: Quality Factor, Ring Resonator, Add Drop Filter, Photonic Crystal, Photonic Band Gap

Posted Date: March 4th, 2021

DOI: https://doi.org/10.21203/rs.3.rs-259817/v1

License: (1) This work is licensed under a Creative Commons Attribution 4.0 International License.

Read Full License 


\title{
Rounded Square Ring Resonator based Add Drop filter for WDM Applications using Two Dimensional Photonic Crystals
}

\author{
Massoudi Radhouene ${ }^{1,2}$ V R Balaji ${ }^{3}$ Monia Najjar $^{2,4}$, S.Robinson ${ }^{5}$, Vijay Janyani ${ }^{6}$, M.Murugan $^{7}$ \\ ${ }^{1}$ ESPRIT School of Engineering Tunisia \\ ${ }^{2}$ University of Tunis El Manar, National Engineering School of Tunis Communications Systems LR-99-ES21(LR- \\ Sys'Com-ENIT), 1002, Tunisia \\ 3 School of Electronics Engineering, Vellore Institute of Technology, Vandalur - Kelambakkam Road, Chennai, \\ Tamil Nadu - 600 127, India. (photonics.material@gmail.com) (ORCID- 0000-0002-9239-7724) \\ ${ }^{4}$ University of Tunis El Manar, Higher Institute of Computer, Ariana, 2080, Tunisia \\ ${ }^{5}$ Mount Zion College of Engineering and Technology Pudukkottai-622 507, Tamilnadu, India \\ ${ }^{6}$ Department of Electronics \& Comm. Engineering, Malaviya National Institute of Technology, Jaipur, India \\ ${ }^{7}$ SRM Valliammai Engineering College, Kattankulathur, 603203, Tamilnadu, India.
}

\begin{abstract}
In this paper, two dimensional photonic crystal based Add Drop filter is designed for DWDM applications. The existing work concentrate in Coarse Wavelength Division Multiplexing (CWDM) and few filter design with DWDM with non-uniform channel spacing, and low quality factor. . The proposed Add Drop Filter (ADF) enhances the quality factor using Rounded Square Ring Resonator (RSRR) for ensuring efficient bandwidth in supporting WDM systems. The design consists of bus waveguide, drop waveguide and RSRR with inner quasi-square ring in the square lattice while dielectric constant of the Si rod is 11.68 which are hosted in the air. The line defect was created by removing 4 rods (Quasi ring) in the center of the inner square ring. The line defects in the cavity help to reduce the radiation field components surrounded by the resonator. The proposed design drops the unique wavelength $1636.2 \mathrm{~nm}$ from a spectrum. The performance parameters of ADF are investigated using 2D Finite Difference Time Domain (FDTD) algorithm. The proposed ADF drops the narrow bandwidth of $0.7 \mathrm{~nm}$, high quality factor of 2337, dropping efficiency (ON State) of $100 \%$, which is highly sufficient to support WDM systems for future Photonic Integrated Circuits (PIC). Further, the impact of functional parameters such as transmission efficiency, quality factor, bandwidth are investigated by varying the structural parameters, namely, adjacent rod radius, scatterer rod radius, coupling rod radius, lattice constant, inner rod radius and rod radius. The size of the device is $412.76 \mu \mathrm{m}^{2}$.
\end{abstract}

\section{Keywords}

Quality Factor, Ring Resonator, Add Drop Filter, Photonic Crystal, Photonic Band Gap. 


\section{Introduction}

The Optical fiber communication sends the information with the pulses of light with less Bit Error Rate (BER) and high Signal to Noise Ratio (SNR) compared with the Radio Frequency (RF). In optical communication, the Single Mode Fiber (SMF) transfers the light for long distance and reaches the receiver end and hence the wavelength drop and added to the filter. Existing optical drop filter designs are as given by Fabry-Perot cavity (Tran et al.1996), gratings (Kersey et al.1993), interferometers (Wooten et al.1996) and the microwave ring resonator by Sun (2011). Nevertheless, this technology has limits in crosstalk, with low quality factor, more bending loss, low speed, and footprint in millimeter. The Photonic technology reduces the limitations and supports the ultra-high speed information processing, on nanoscale devices for integrating in PIC.

The Photonic crystal (PC) is a man-made artificial crystal, made of periodic dielectric material in space, acts as a potential barrier for the electromagnetic waves (Joannopoulos et al.1997). The PC allows and forbids certain waves to design any applications within the structure. The Photonic Band Gap (PBG) is a needed property in the PC. The incident light in PBG cannot propagate in the crystal, however; the light can be allowed to propagate with breaking the periodicity in the PC, introducing the defect in the PC allowing the electromagnetic waves to confine strongly based on the defects. So, based on the defects the PC guides the select resonant frequency in spite of tunneling effect. The defect is classified as line defect for designing waveguides and point defect for the resonator.

The kind of PC classified as one-dimensional (1D). The 1D was reported in 1887 by Lord Rayleigh, but it took another 10 decades to introduce the 2D and 3D PC by Thomas Krauss. The 2D PC provides better PBG compared with a 1D PC to provide high speed information processing. Also, the 2D fabrication is simple compared with 3D PC. Therefore, the $2 \mathrm{D}$ PC is a better choice for designing optical devices due to many advantages such as nano size, complete PBG and better light manipulation to integrate in PIC. The 2D PC design with diverse components like LASER (Meier et al.1999), filter (Fan et al.1998), sensor (Fenzl et al.2014), demultiplexer (Balaji et al 2016), logic gates (Zhang et al 2007), encoder (Mehdizadeh et al.2017), Micro ring resonator (Ali Shahidinejad et al 2018), Add Drop filter (Joannopoulos et al.1997; Hsiao et al.2009; Mahmoud et al.2012; Rajasekar et al.2018; Sathyadevaki et al.2017; Qiang, et al.2004; Alipour-Banaei et al.2014; Robinson et al.2018; Rezaee et al.2018; Rashki et a.2017; Chhipa et al.2016, Alipour-Banaei et al.2014; Massoudi et al.2019) and etc. 
One of the important components to work in the Wavelength Division Multiplexing (WDM) system is ADF. The filter drops the desired wavelength, through the remaining spectrum to the optical communication network. The filter used in Photonic switches (Beggs et al.2008), Modulators (Jiang et al.2005). In the literature survey optical filter designed in Square lattice (Joannopoulos et al.1997) and Hexagonal lattice (Joannopoulos et al.1997) using resonant cavity like Hexagonal (Hsiao et al.2009) shape, $X$ shape (Mahmoud et al.2012), Trapezoid shape (Rajasekar et al.2018), Square shape (Sathyadevaki et al.2017), Quasi square shape (Qiang, et al.2004; Alipour-Banaei et al.2014),Circular shape(Robinson et al.2018), H shape (Rezaee et al.2018), Flower shape (Rezaee et al.2018), Curved Fabry Perot shape (Rashki et a.2017), Elliptical shape (Chhipa et al.2016), and Super Elliptical shape (Massoudi et al.2019).

From the literature survey, it is inferred that most of the drop filters are designed using different shapes of the resonant cavity. Many designs provide better performance in drooping efficiency and device size. However, the parameters like Q factor and narrow spectral linewidth need the improvement in the ADF to meet the ITU standards for on demand applications like Voice over IP high-speed internet, and High Definition Television (HDTV). Hence, in this paper, a new square shape ring resonator Add Drop Filter is proposed. The proposed filter design to work with constructive interference to obtain the high dropping efficiency (>99\%), narrow spectral linewidth $(0.7 \mathrm{~nm})$, and high Q factor (2223) at resonance wavelength of $1636.2 \mathrm{~nm}$ is reported. The high Q factor is obtained with increasing the rod between waveguide and cavity (Fan et al.2002).

Further, the proposed filters are investigated and reported with structural parameters to tune the different strong resonant wavelengths to improve the utilization of the device in many applications. The Band gap analysis of the proposed filter before and after the defects are studied with Plane Wave Expansion (PWE) Method (Shi et al.2004) and The dropping spectrum and transfer spectrum measured through the FDTD algorithm. (Qiu et al.2001).

The paper is organized as follows; The section 2 discusses the structural parameter and gap map analysis for the lattice. The proposed design and working principle are discussed in section 3. The section 4 discusses the simulation results for add drop filter. Investigation of the tuning mechanism for the drop filter is discussed in section 5. Finally, the section 6 concludes the paper.

\section{Photonic Band Gap Structure}

A semiconductor is a promising material for manufacturing electronic devices due to the presence of Electronic Band Gap. The photonic device emerges due to the existing Photonic Band Gap (PBG) in selected semiconductor material in order to design the optical 
communication devices. Nonetheless, these materials should have two properties for optical manipulation such as high refractive index contrast and suitable for nanofabrication.

The proposed Add Drop Filter (ADF) design with a square lattice array of periodic dielectric rods with high refractive index of 3.19, regular radius of rod of $130 \mathrm{~nm}$, Period (lattice constant) of $650 \mathrm{~nm}$ which results in useful Photonic crystal band gap for realizing optical device. The periodic dielectric rods permit the Transverse Electric (TE) wave through which Magnetic field parallel to the rod. The proposed filter is designed with the dimension of $35 \times 28$ in $\mathrm{X}$ and $\mathrm{Z}$ direction. The PBG before defects is calculated using the PWE and is given in Fig.1.

The band diagram of proposed ADF consists of two TE PBGs, first TE PBG normalized frequency in the range of $0.296<\mathrm{a} / \lambda<0.432$ and wavelength between $1504 \mathrm{~nm}$ to $2195 \mathrm{~nm}$, which covers a wide range of optical communication band that are genuinely used for designing optical network devices. The second TE band gap varies from $0.746<\mathrm{a} / \lambda 0.763$ and corresponding wavelength are $851 \mathrm{~nm}$ to $870 \mathrm{~nm}$, which is outside the optical communication window and hence not preferred for the proposed design.

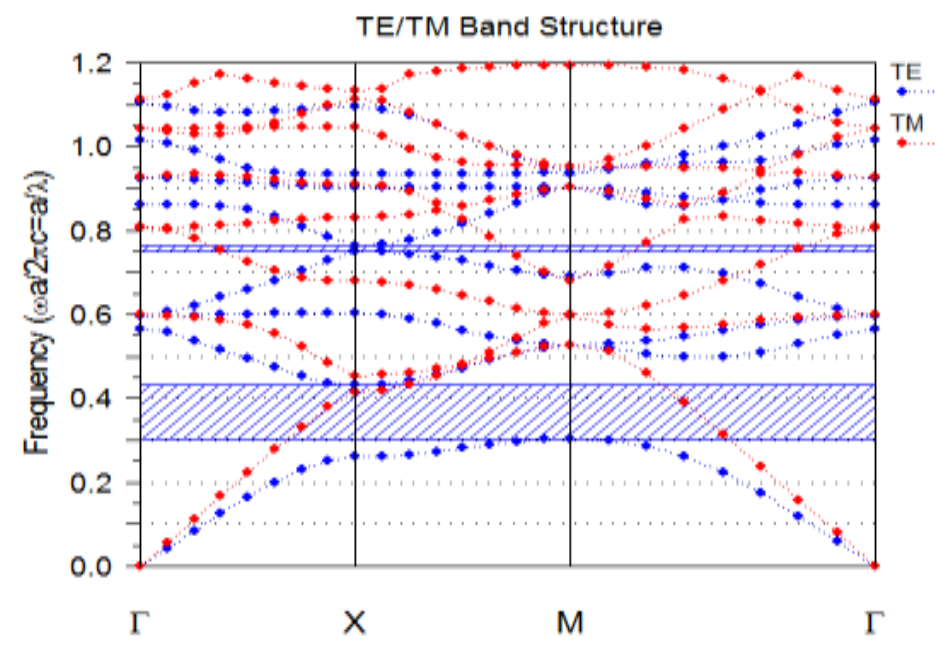

Fig.1 PBG before introducing the defects

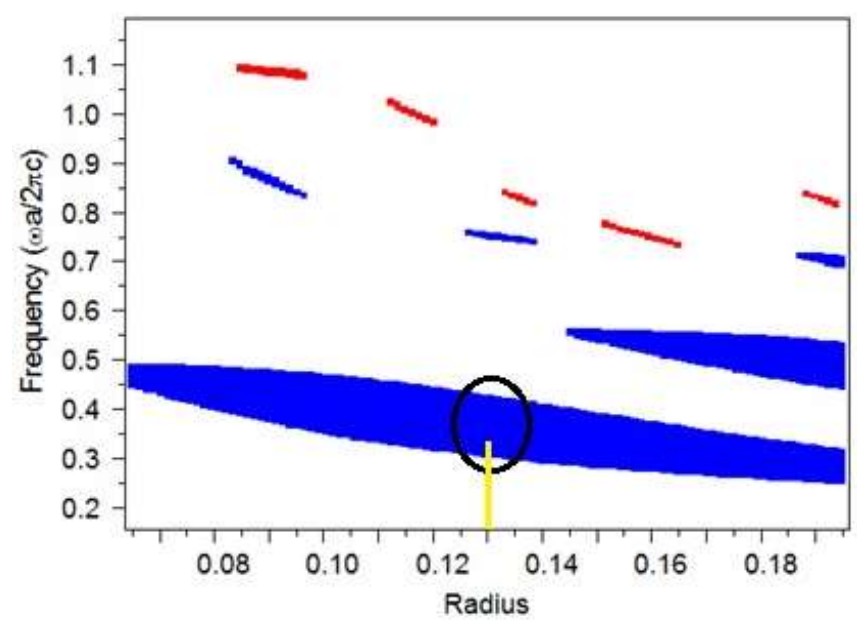


Fig.2 Effects of normalized frequency with respect to the rod radius

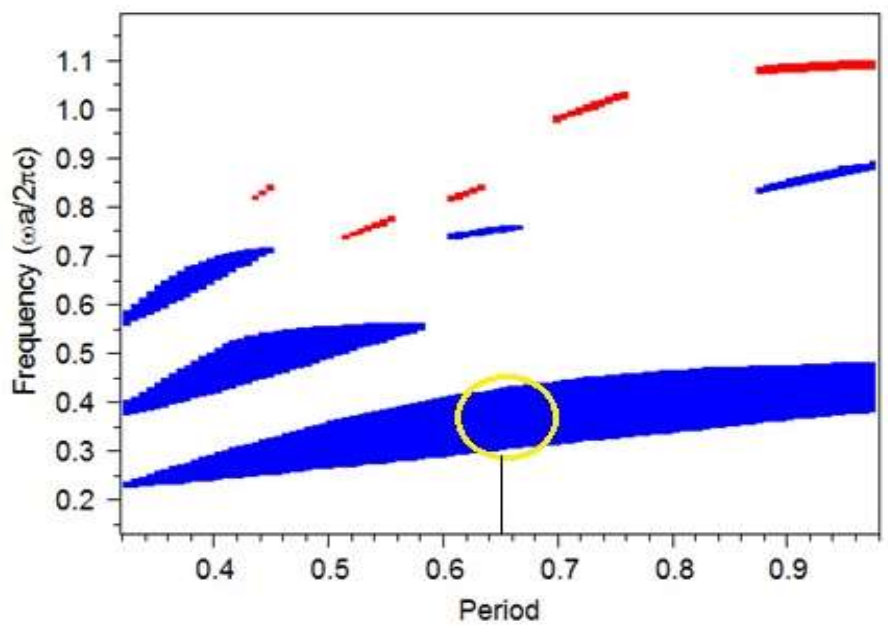

Fig.3 Effects of normalized frequency with respect to the lattice constant (period)

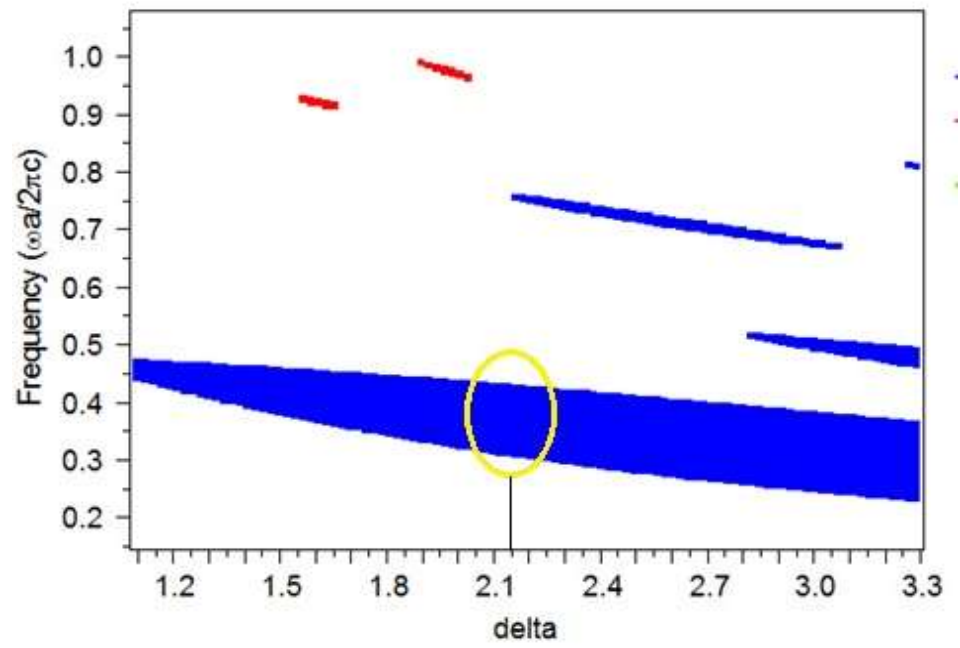

Fig.4 Effects of normalized frequency with respect to the refractive index difference (delta)

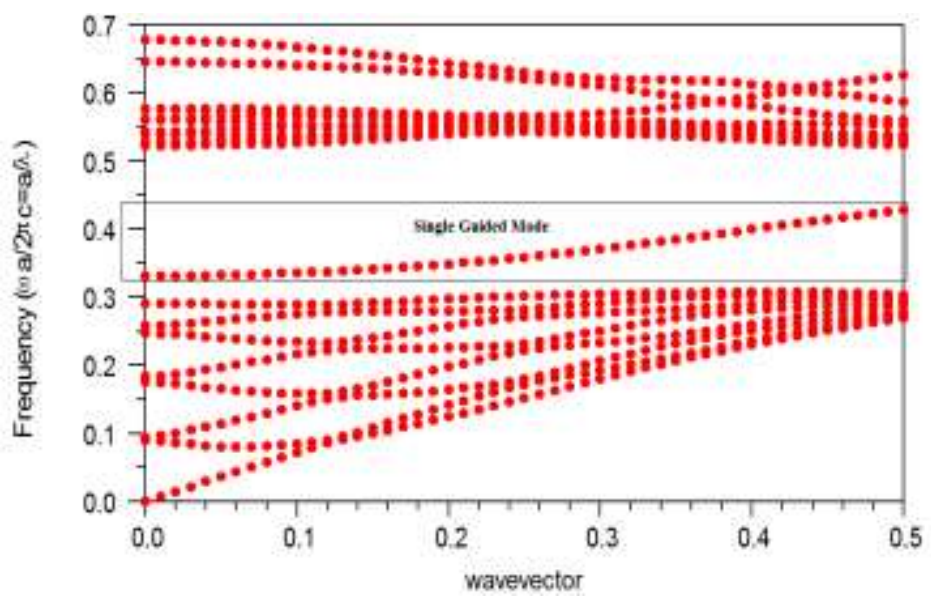

Fig.5 Band gap diagram after introducing line and point defects

The optimization of structural parameter with normalized frequency is calculated using PWE method. The structural parameter of rod, lattice constant (period), refractive index 
(delta) to be optimized in the wavelength range of the optical communication wavelength. In the Fig.2, the optimized rod radius (R) for the proposed filter is $130 \mathrm{~nm}$ and lattice constant (a) tuned to $650 \mathrm{~nm}$ is shown in Fig.3, and refractive index is optimized with 3.19 for the signal of interest is shown in Fig.4. The guided mode after introducing the defects in the lattice is shown in Fig.5. At resonance frequency, the resonant wavelength tunneling in the PBG is based on the defects.

\section{Rounded Square Ring Resonator based Add Drop Filter}

\subsection{Basic Mechanism}

Fig.6 shows the architecture of the WDM network. The four different wavelengths with the spectral linewidth of $0.8 \mathrm{~nm}$ arrive from the main office. The SMF is used as medium from the main office to transfer the user data to receiver end for the different applications. The $\mathrm{ADF}$ is a prominent device in the network to select or drop the desired wavelength to the network without disturbing the other wavelength from the SMF (Park et al.2004).

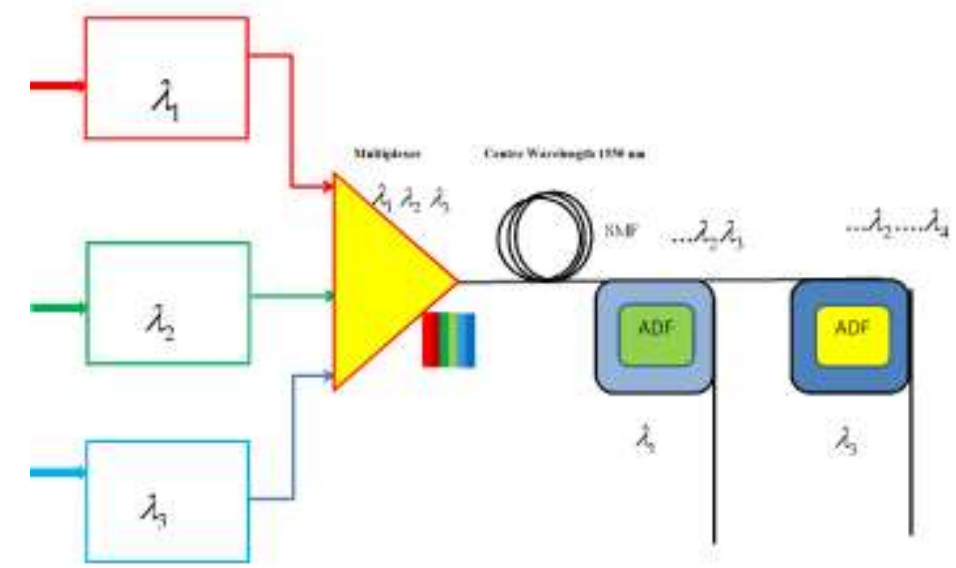

Fig.6 Schematic representation of WDM network with Add Drop Filter

ADF plays an important role in fiber communication systems. ADF consists of the four ports, namely, Port A, Port B, Port C and Port D .The Port A is the input port, Port B is a Transmission Port, Port C is a backward drop port, and Port D is a forward drop port. The basic structure of ADF consists of ring microcavity and side couple two optical waveguides, resonant cavity slot in between the waveguides. For communication applications, the ADF works in two desirable functions like ON and OFF state. The input Port A allows the WDM signal $\left(\lambda_{1} \lambda_{2} \lambda_{3} \lambda_{4}\right)$ (Refer Fig.6.) in the ADF.

In ON state, unique resonant frequency $\left(\boldsymbol{\lambda}_{1}\right)$ get resonance inside the cavity, completely (100\%) light signal transfer to drop waveguide (Port C) via resonant cavity with the principle of the Photonic Tunneling effect. The signal coupling to drop waveguide based on the structural parameters like regular rod radius, scatterer rods, coupling rods and adjacent rods. The maximum efficiency of light can be transferred from the bus waveguide (Port A) to 
drop waveguide (Port C) through cavity should follow the condition $k d=(n+1 / 2) \pi$, where; $k$ is the wave vector, $\mathrm{n}$ is the integer, and $\mathrm{d}$ is the distance between the two optical cavities. However, the Transmission Port (Port B) transfers all other wavelengths other than the resonant frequency and zero power transmission in Forward drop (Port D) port which is shown in Fig.7(a). In OFF state, signal is not transferred between the Bus waveguide and drop waveguide. The signal lies in the bus waveguide at Transmission port (Port B) which is shown in Fig.7(b).

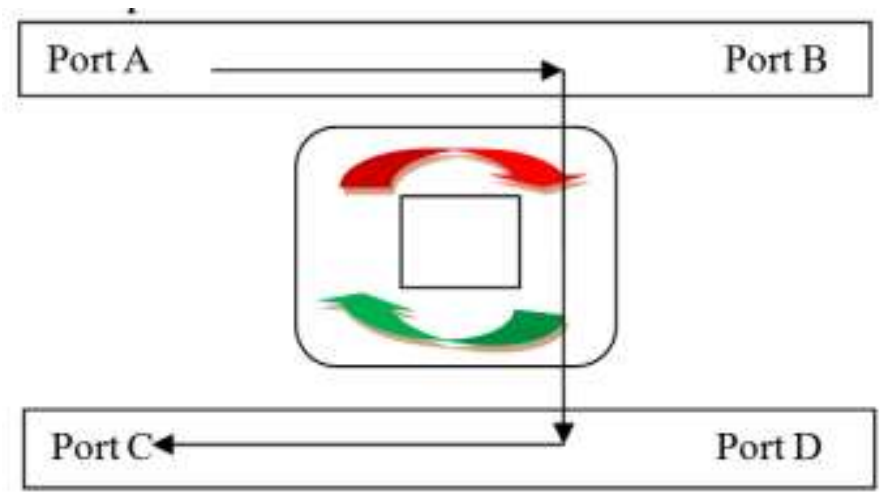

(a)

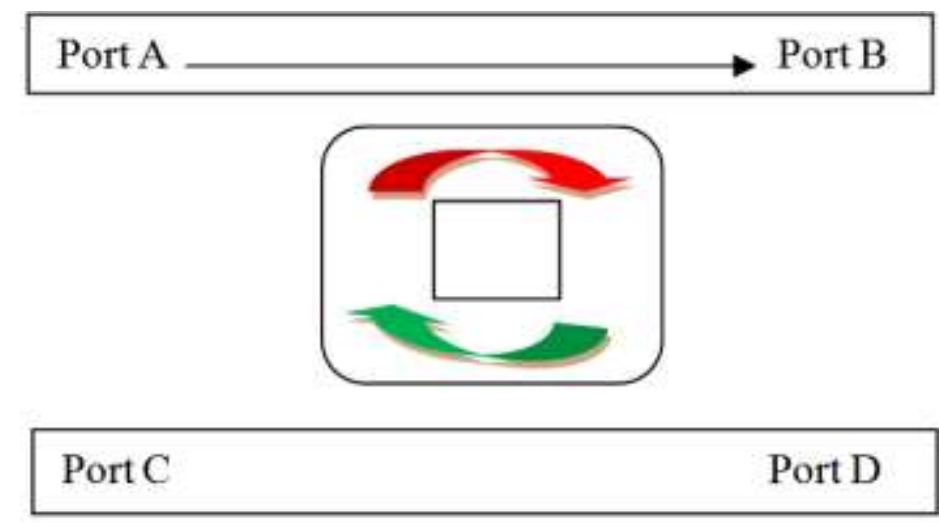

(b)

Fig.7.ADF response at (a) ON state (b) OFF state

\subsection{Proposed Add Drop Filter}

The proposed RSRR ADF is shown in Fig. 8. The filter is designed with rounded square ring resonator with four ports. The line defect is introduced in 2D PC lattice to design bus and drop waveguide. The RSRR allows the electric field waves to build a round trip with the phase shift of $2 \pi$ for the different waves, which provide constructive interference. The interference in the cavity provides a high resonant peak in certain frequency. The RSRR designed by removing the 9 rods on each side to bring the square shape cavity and 4 scatterer rods in the corner it shapes the rounded shape square cavity. Inner ring design with 32 rods and 4 center rods removed to design quasi square. The entire structure of the structural parameter uses the regular rod radius of $130 \mathrm{~nm}$. The removal of center rod influence to 
reduce the radiation field scattering, which help to enhance the coupling efficiency to the Port C. The single rod placed at each corner of square act as scatterer rods (R3) which is highlighted in green color it minimizes the scatter loss, and back and forth reflection waves improve the resonator performance.

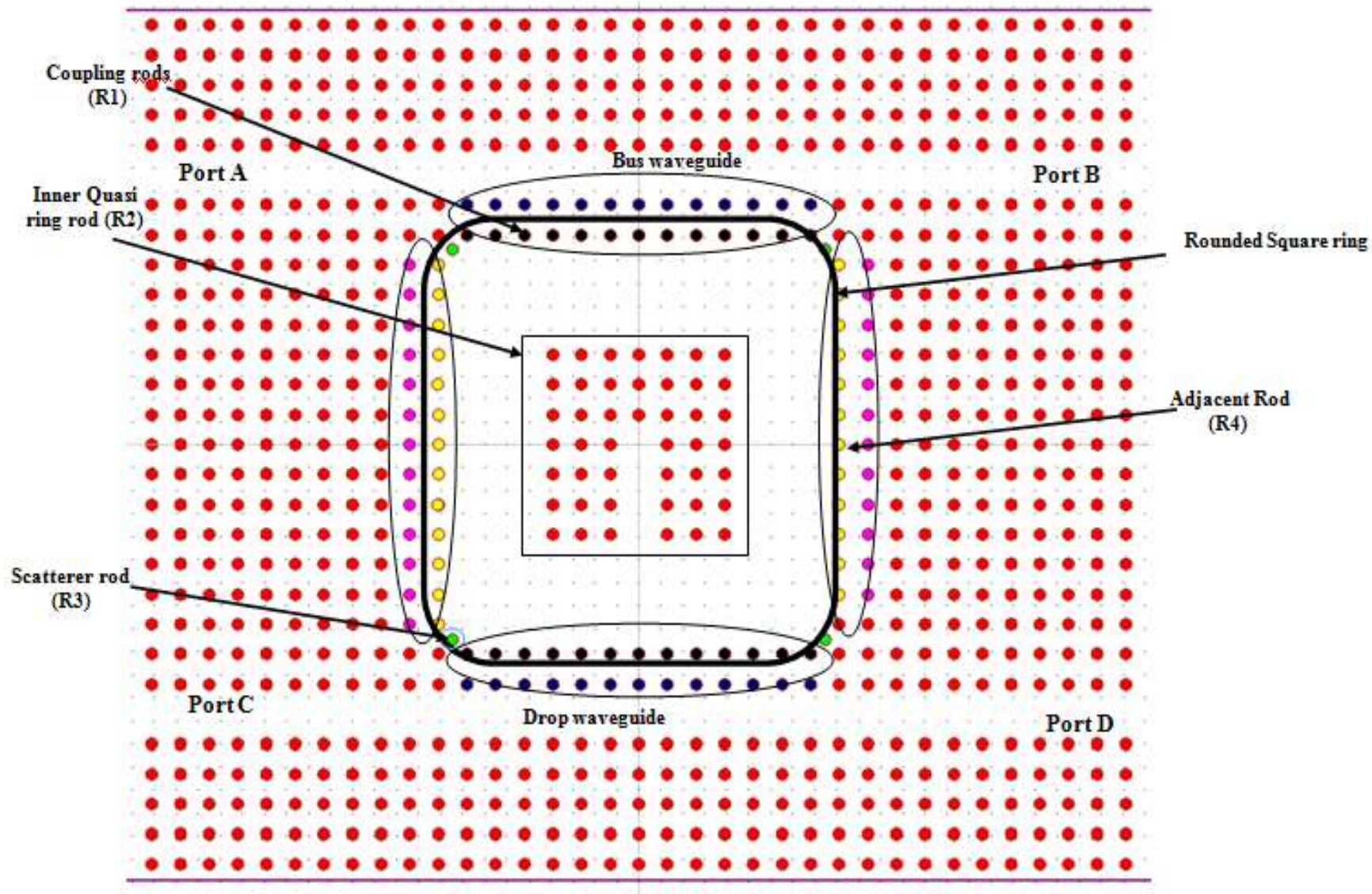

Fig. 8 Proposed Rounded Square Ring resonator based Add Drop filter

The coupling rods (R1) in the outer edge of the square cavity help to couple the photons to the drop (Port D) and add (Port B) waveguide port which is highlighted in dark black and blue color. The coupling rod radius is important to get higher coupling efficiency and it provides the better confinement of signal to drop waveguide. The coupling rod radius varied from $129 \mathrm{~nm}-133 \mathrm{~nm}$ to find the best rod radius with transmission efficiency is shown in Fig.14.

The coupling rod radius $(130 \mathrm{~nm})$ provides the higher dropping efficiency in Port $\mathrm{C}$ compare to other rod radius with narrow spectral linewidth of $0.7 \mathrm{~nm}$, and quality factor of 2223. Hence it is considered for the proposed design. Best of our knowledge, this is the first time to report all structural parameters like adjacent rods, scaterrer rods, inner quasi ring rod, and coupling rods are design same as regular rod radius of $130 \mathrm{~nm}$. The regular rod radius of $130 \mathrm{~nm}$ optimizes after the several iterations to get the best size to provide the better performance parameters in the proposed ADF and it's easy to fabricate. 


\section{Simulation Results and Discussion}

The transmission spectrum of the proposed filter measure is based on the received power in the Port B, Port C, Port D. The power monitor place in the receiver port to measure the power based on Finite Difference Time Domain (FDTD) algorithm .The output power measure using the following equation,

$$
T(f)=\frac{1 / 2 \int \operatorname{real}\left(p(f)^{\text {monitor }}\right) \mathrm{dS}}{\text { SourcePower }}
$$

Where, $T(f)$ denotes the function transmission as function of wavelength, $p(f)$ denotes the pointing vector, and $\mathrm{dS}$ denotes the surface normal.

The 2D Finite Difference Time Domain (FDTD) works with the Perfect Matched Layer Absorbed Boundary Condition (PML ABC). The PML ABC is an artificial boundary layer to support the simulation in open boundary condition (Free space), layer strongly absorbs the all incident waves in all directions, angle without any reflection inside the PC lattice (Chew et al.1996). The proposed ADF filter uses the PML width of $500 \mathrm{~nm}$, and reflection of $10^{-8}$ for the best performance.

To work in FDTD, it is important to choose the proper spatial and temporal grid size and time step to match the simulation output with a real time system (Xiao et al.1993). The proper grid size is calculated using the a/16 $=40 \mathrm{~nm}$ and time step of $\Delta_{\mathrm{t}}=0.02203$ is used in the FDTD algorithm, it provides stable output and less time leads to oscillation output. The time step calculated by

$$
\Delta t \leq \frac{1}{c \sqrt{\frac{1}{\Delta X^{2}}+\frac{1}{\Delta Y^{2}}}}
$$

Where, $\Delta t$ denotes the step time, $\mathrm{C}$ denotes the speed of light in free space respectively.

The WDM multiplexed signal launched in the input Port A with the center wavelength of $1550 \mathrm{~nm}$. The resonant optical wavelength $(1636.2 \mathrm{~nm})$ coupled to the resonator with the coupling rods (R1) through the drop waveguide. The resonator gets a peak resonance and drops the output power to Port $\mathrm{C}$ and remaining wavelength forward to Port $\mathrm{B}$ and a small amount of scattering power transferred to Port D. 


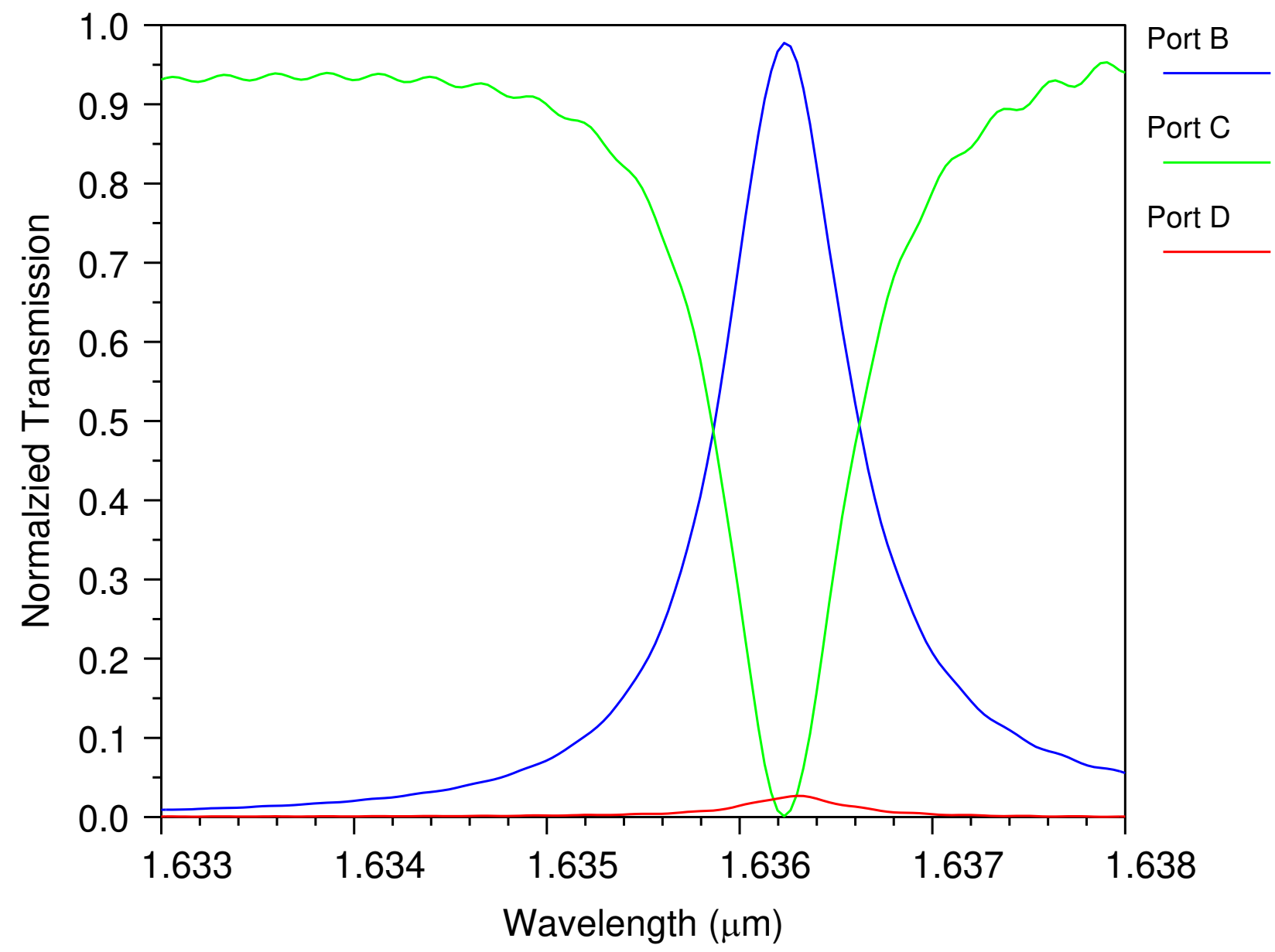

Fig.9 Normalized output spectrum of the proposed Add Drop filter

The Fig.9 shows the normalized output spectrum at the strong wavelength peak at $1636.2 \mathrm{~nm}$ in the dropping Port $\mathrm{C}$ with close to Transmission efficiency of $100 \%$. The spectral Full Width Half Maximum (FWHM) at $0.7 \mathrm{~nm}$. The efficiency of the filter is calculated using the quality factor $(\mathrm{Q})$. The $\mathrm{Q}$ factor is measured by the formula (Ohteru, et al.1993)

$$
Q=\frac{\lambda}{\Delta \lambda}
$$

Where $\lambda$ is the strong resonant wavelength and $\Delta \lambda$ is spectral linewidth (FWHM) of the resonant wavelength. The proposed Add Drop filter drop the $1636.2 \mathrm{~nm}$ optical wavelength and high quality factor about 2337, which is more suitable for WDM systems. 

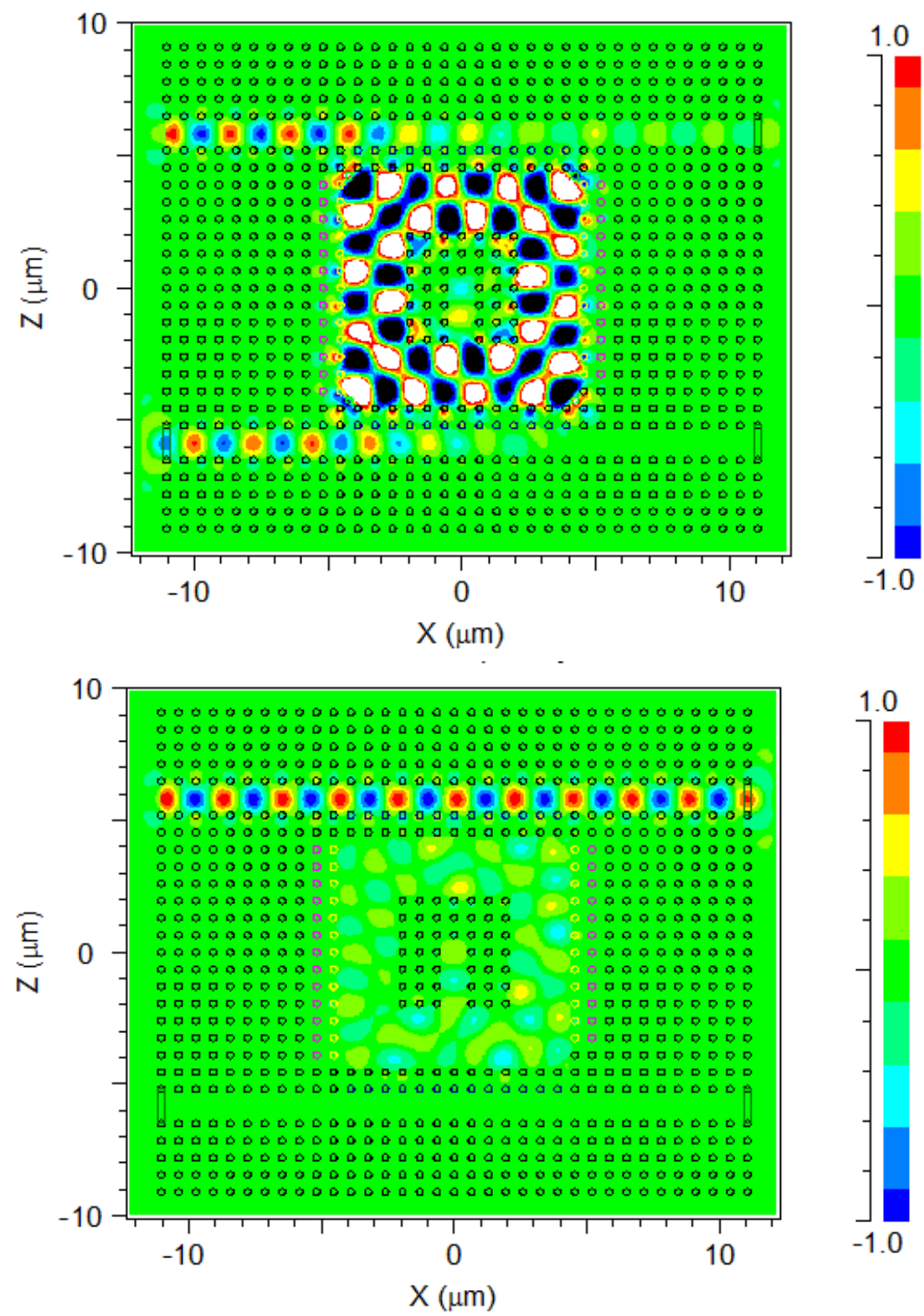

Fig.10 Electric field distribution of the proposed Add Drop filter at (a) ON resonance $(1636.2 \mathrm{~nm})$ and (b) OFF resonance $(1633 \mathrm{~nm})$

The field pattern for backward drop optical power at Port $\mathrm{C}$ is shown in Fig. 10. The optical power at the resonant wavelength move towards Port $\mathrm{C}$ and other than resonant wavelengths transferred to Port B and no power at Port D. The proposed drop filter reduces the complexity of fabrication by reducing the defects. The defects rod radius $130 \mathrm{~nm}$ optimize globally after tuning of refractive index, lattice constant, and shape to drop the desired wavelength.

\section{Parameters affecting the performance of the ADF}

The proposed ADF drops the resonant wavelength at $1636.2 \mathrm{~nm}$ with high $\mathrm{Q}$ factor to support WDM systems. To broaden the utilization of ADF in real time and on demand applications, tuning mechanism of ADF is investigated by varying the structural parameter and properties like adjacent rods, scatter rods, inner quasi-square rods, periods, coupling rod 
radius and radius of regular rods. The proposed PBG in the range of $0.292<\mathrm{a} / \lambda<0.432$, as a structural parameter varies, resonant wavelength from ADF also drops the different resonant wavelength within the PBG. The value of structural parameter is increased propagation of guided mode in ADF shifted in higher wavelength and corresponding strong resonant peak is dropped.

\subsection{Lattice constant Tuning}

Lattice constant of the structure is varied with an increment of $1 \mathrm{~nm}$ from $650 \mathrm{~nm}$ to $655 \mathrm{~nm}$ to measure the sensitivity of lattice constant with resonant wavelength. The normalized output spectrum for different lattice constant is shown in Fig. 11. From the simulation results, it is observed that strong resonant wavelength of the drop filter is shifted to higher wavelength of $1 \mathrm{~nm}$ compared with a reference value of $650 \mathrm{~nm}$ also small variation in normalized transmission and spectral linewidth remain constant. Performance parameters of ADF with the variation of lattice constant are given in the Table1.

$$
s_{L}=\frac{\Delta \lambda}{\Delta \text { Lattice Constant }}=\frac{0.2}{1}=0.2 \mathrm{~nm}
$$

The changes of lattice constant are highly sensitive to resonant wavelength Tuning.

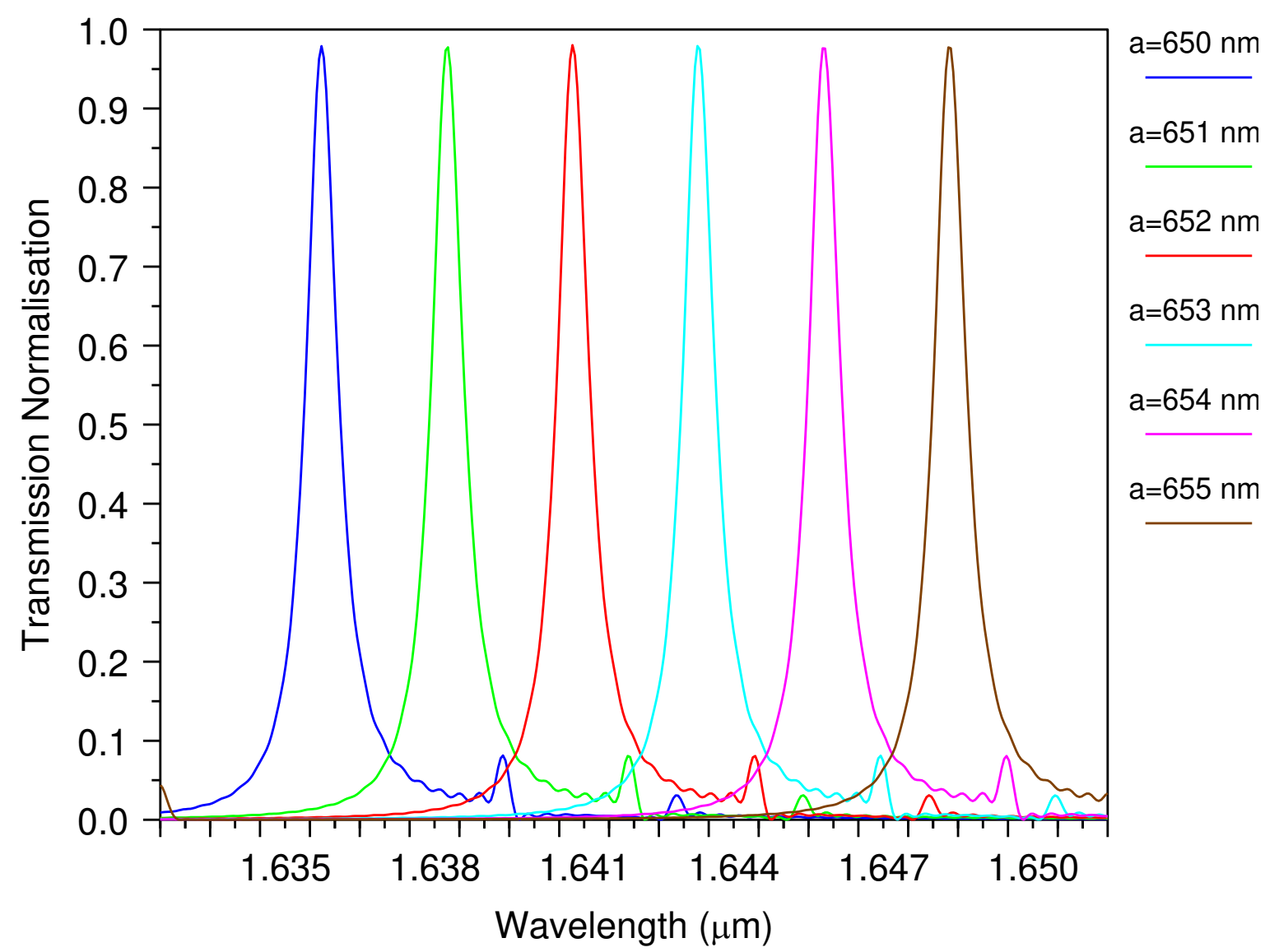

Fig.11. Output spectrum for different lattice constant 
Table 1. Performance parameter with the changes of Lattice constant (a) with performance parameters like resonant wavelength, normalized transmission, spectral linewidth, and quality factor

\begin{tabular}{|l|c|c|c|c|c|}
\hline S.no & $\begin{array}{c}\text { Lattice } \\
\text { Constant } \\
(\mathrm{nm})\end{array}$ & $\begin{array}{c}\text { Resonant } \\
\text { Wavelength } \\
(\mathrm{nm})\end{array}$ & $\begin{array}{c}\text { Normalized } \\
\text { Transmission } \\
(\%)\end{array}$ & $\begin{array}{c}\text { Spectral } \\
\text { Linewidth } \\
(\mathrm{nm})\end{array}$ & $\begin{array}{c}\text { Quality } \\
\text { Factor }\end{array}$ \\
\hline 1. & 650 & 1630.3 & 97.8 & 0.7 & 2329 \\
\hline 2. & 651 & 1630.5 & 97.4 & 0.7 & 2329 \\
\hline 3. & 652 & 1630.7 & 97.8 & 0.8 & 2038 \\
\hline 4. & 653 & 1630.9 & 97.8 & 0.8 & 2038 \\
\hline 5. & 654 & 1631.1 & 97.6 & 0.7 & 2330 \\
\hline 6. & 655 & 1631.4 & 97.6 & 0.8 & 2039 \\
\hline
\end{tabular}

\subsection{Effect of Adjacent rod Radius}

In ADF, the reference rod radius of the adjacent rod ( $R$ 4) is $130 \mathrm{~nm}$. The impact of adjacent rod radius with ADF geometry is analyzed with increasing the rod radius with a step value of $1 \mathrm{~nm}$ from $131 \mathrm{~nm}-133 \mathrm{~nm}$ is observed while other structural parameters are constant to find the sensitivity of adjacent rod. The Fig.12 shows the normalized spectrum for different adjacent rod radius. The performance parameter of R4 is tabulated in Table 2. From the results, strong resonant wavelength shift by $0.3 \mathrm{~nm}$ to higher wavelength with correspondingly dropping efficiency and quality factor slightly increased but spectral linewidth $(0.8 \mathrm{~nm})$ remain constant.

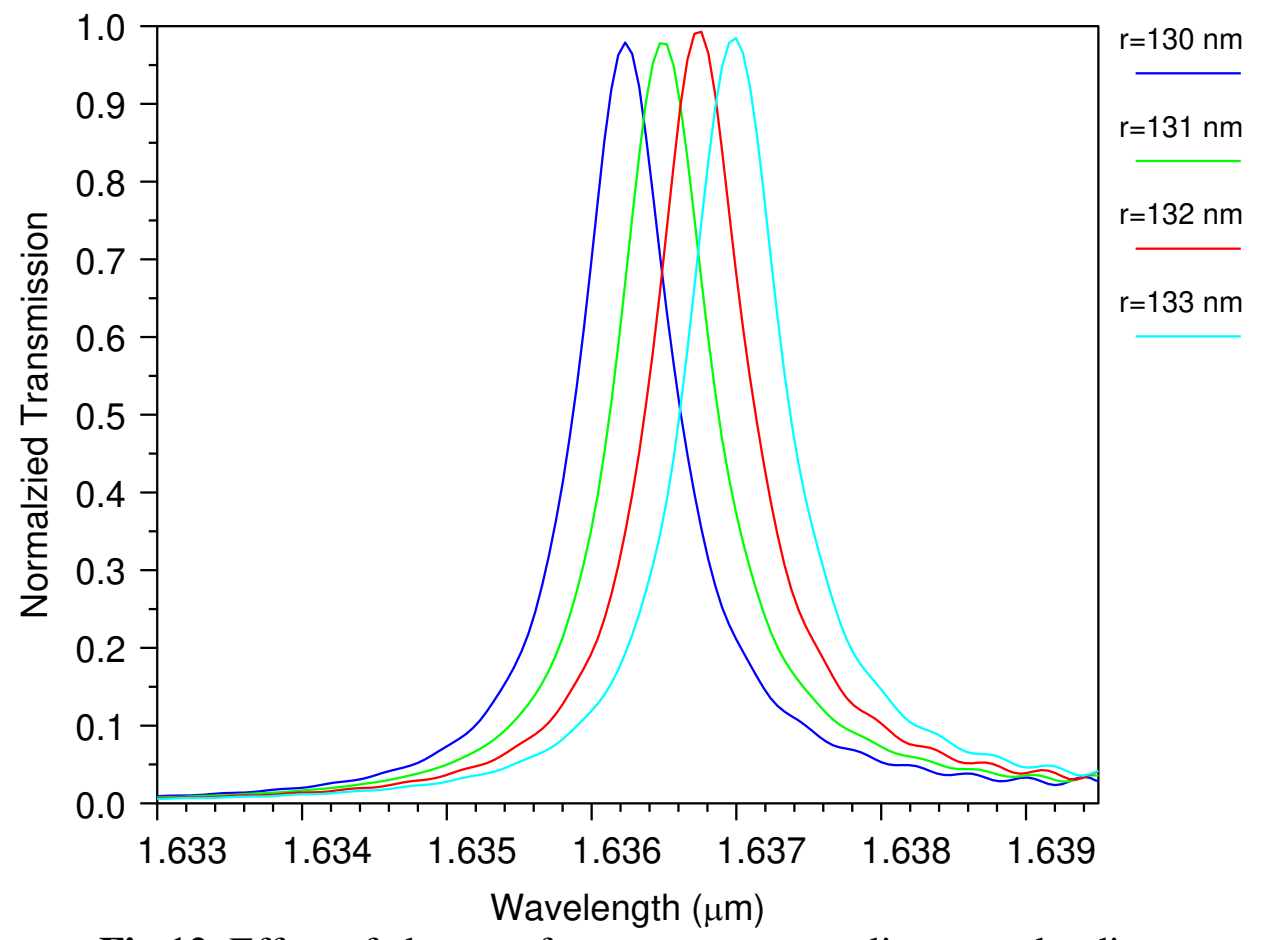

Fig.12. Effect of change of output spectrum adjacent rod radius

Through analyzing the tuning mechanism of different wavelength to the proposed $\mathrm{ADF}$, the sensitivity of adjacent rod with resonant wavelength is measured from the equation. 


$$
S_{A}=\frac{\Delta \lambda}{\Delta \mathrm{R} 4}=\frac{0.3}{1}
$$

The sensitivity of adjacent rod is 0.3 resonant wavelengths tuning is highly sensitive to changes of adjacent rod and it's important to observe spectral linewidth and Normalized transmission remain constant.

Table 2. Performance parameter with the changes of adjacent rod radius (R4) with performance parameters like resonant wavelength, normalized transmission, spectral line width, and quality factor

\begin{tabular}{|c|c|c|c|c|c|}
\hline S.no & R4 (nm) & $\begin{array}{c}\text { Resonant } \\
\text { Wavelength } \\
(\mathrm{nm})\end{array}$ & $\begin{array}{c}\text { Normalized } \\
\text { Transmission } \\
(\%)\end{array}$ & $\begin{array}{c}\text { Spectral } \\
\text { Linewidth } \\
(\mathrm{nm})\end{array}$ & $\begin{array}{c}\text { Quality } \\
\text { Factor }\end{array}$ \\
\hline 1. & 130 & 1636.0 & 98 & 0.8 & 2045 \\
\hline 2. & 131 & 1636.5 & 98.0 & 0.8 & 2045.65 \\
\hline 3. & 132 & 1636.8 & 99.2 & 0.8 & 2046 \\
\hline 4. & 133 & 1637.1 & 98.4 & 0.8 & 2046.37 \\
\hline
\end{tabular}

\subsection{Scatterer rod tuning}

In ADF, the reference rod radius of the scatterer rod (R3) is $130 \mathrm{~nm}$.Scattered rods are placed at each corner of four sides in the square ring resonator. The scatterer rod reduces the scatter loss and reflection waves from the rod improve the resonator performance. The Scatterer rod tuning impact of change in rod with resonant wavelength is studied. The scatterer rod of the proposed ADF is varied with an increment of $1 \mathrm{~nm}$ from $130 \mathrm{~nm}$ to $132 \mathrm{~nm}$ corresponding output spectrum of different scattered rod radius is investigated which is shown Fig.13. From the simulation results, it observed that peak resonant wavelength shifted by 0.1 $\mathrm{nm}$ from the reference wavelength. The dropping efficiency and quality factor is slight change and spectral linewidth remain constant and is observed by changing scattered rod.

Table 3. Functional parameter with the changes of Scatterer rod radius (R3) with performance parameters like resonant wavelength, normalized transmission, spectral linewidth, and quality factor

\begin{tabular}{|c|c|c|c|c|c|}
\hline S.no & $\begin{array}{c}\text { R3 } \\
(\mathrm{nm})\end{array}$ & $\begin{array}{c}\text { Resonant } \\
\text { Wavelength } \\
(\mathrm{nm})\end{array}$ & $\begin{array}{c}\text { Normalized } \\
\text { Transmission } \\
(\%)\end{array}$ & $\begin{array}{c}\text { Spectral } \\
\text { Linewidth } \\
(\mathrm{nm})\end{array}$ & $\begin{array}{c}\text { Quality } \\
\text { Factor }\end{array}$ \\
\hline 1. & 130 & 1636.0 & 99.0 & 0.7 & 2337.0 \\
\hline 2. & 130.5 & 1636.2 & 99.0 & 0.8 & 2045.25 \\
\hline 3. & 131 & 1636.3 & 95.76 & 0.8 & 2045.37 \\
\hline 4. & 132 & 1636.4 & 81.61 & 0.8 & 2045.5 \\
\hline
\end{tabular}




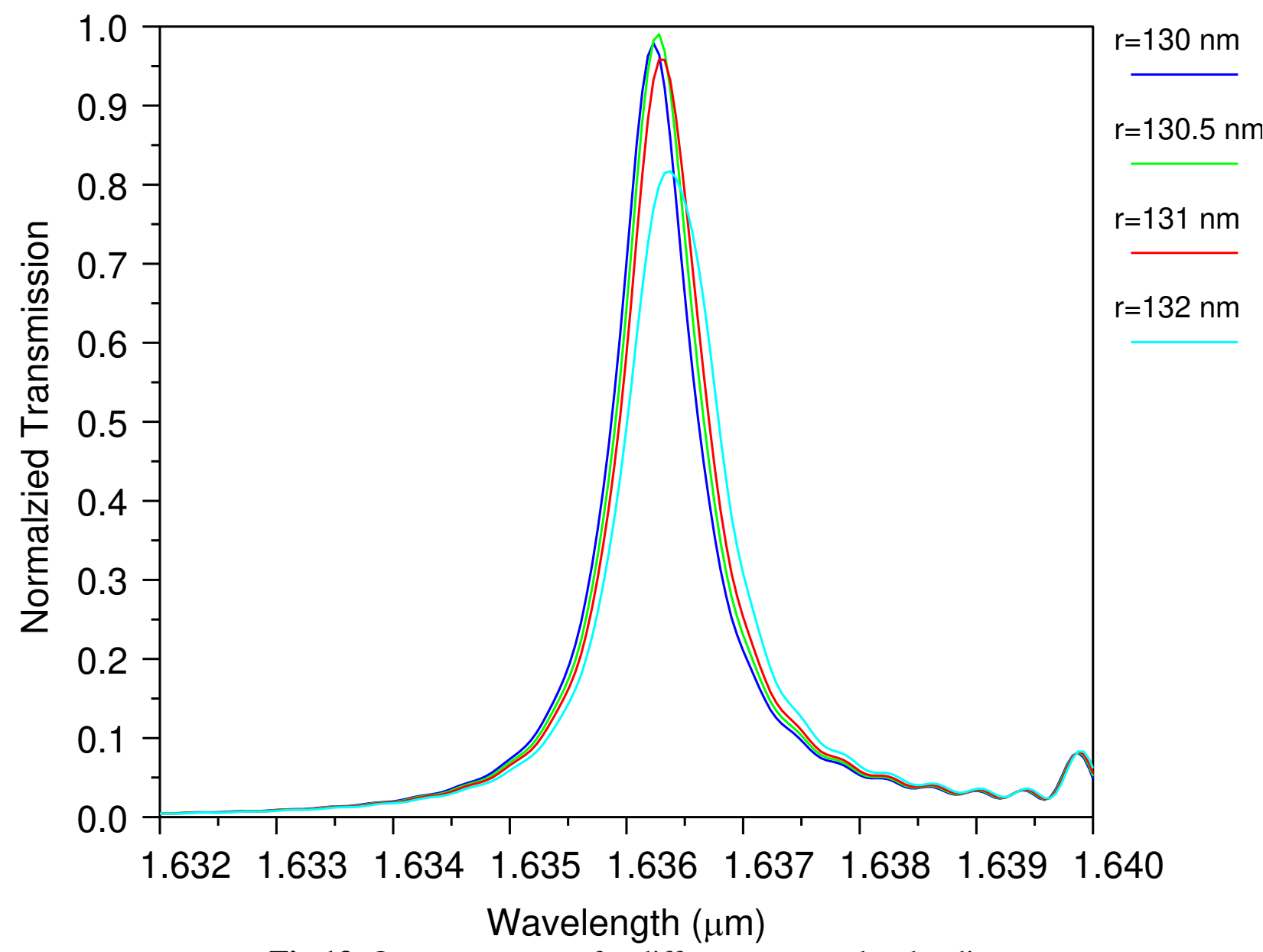

Fig.13. Output spectrum for different scattered rod radius

The sensitivity of Scatterer rod is defined as a resonant wavelength variation with the scatterer rod variation $\Delta \lambda / \Delta \mathrm{R} 3$, sensitivity calculated as $\pm 0.2 \mathrm{~nm} / 1 \mathrm{~nm}$. The performance parameter of R3 is tabulated in Table 3.

\subsection{Coupling rod radius Tuning}

In $\mathrm{ADF}$, the reference rod radius of coupling rod radius (R1) is $130 \mathrm{~nm}$. This rod optimizes with a radius of $130 \mathrm{~nm}$ it used to couple the incoming light from the bus waveguide to drop waveguide through rounded ring square ring resonator. The two rows of rods used for coupling for better coupling light to the resonator. To analyze the impact of variation with coupling rods, the coupling rod radius varied from $130 \mathrm{~nm}-133 \mathrm{~nm}$ with $1 \mathrm{~nm}$ shift. It is observed that zero resonant wavelength is shifted while the trivial decrement of Transmission efficiency is observed for rod radius other than reference rod (130 nm) which is shown in Fig.14. The tuning mechanism in the ADF filter and the coupling rod radius to be fixed as $130 \mathrm{~nm}$, however, the other structural parameters are varied in order to drop different resonant wavelengths. The performance parameter of Radius 1 is tabulated in Table 4. The sensitivity of Scatterer rod is defined as a resonant wavelength variation with the scatterer rod variation $\Delta \lambda \Delta \mathrm{R} 1$, sensitivity in the ratio of $0 \mathrm{~nm} / 1 \mathrm{~nm}$. 


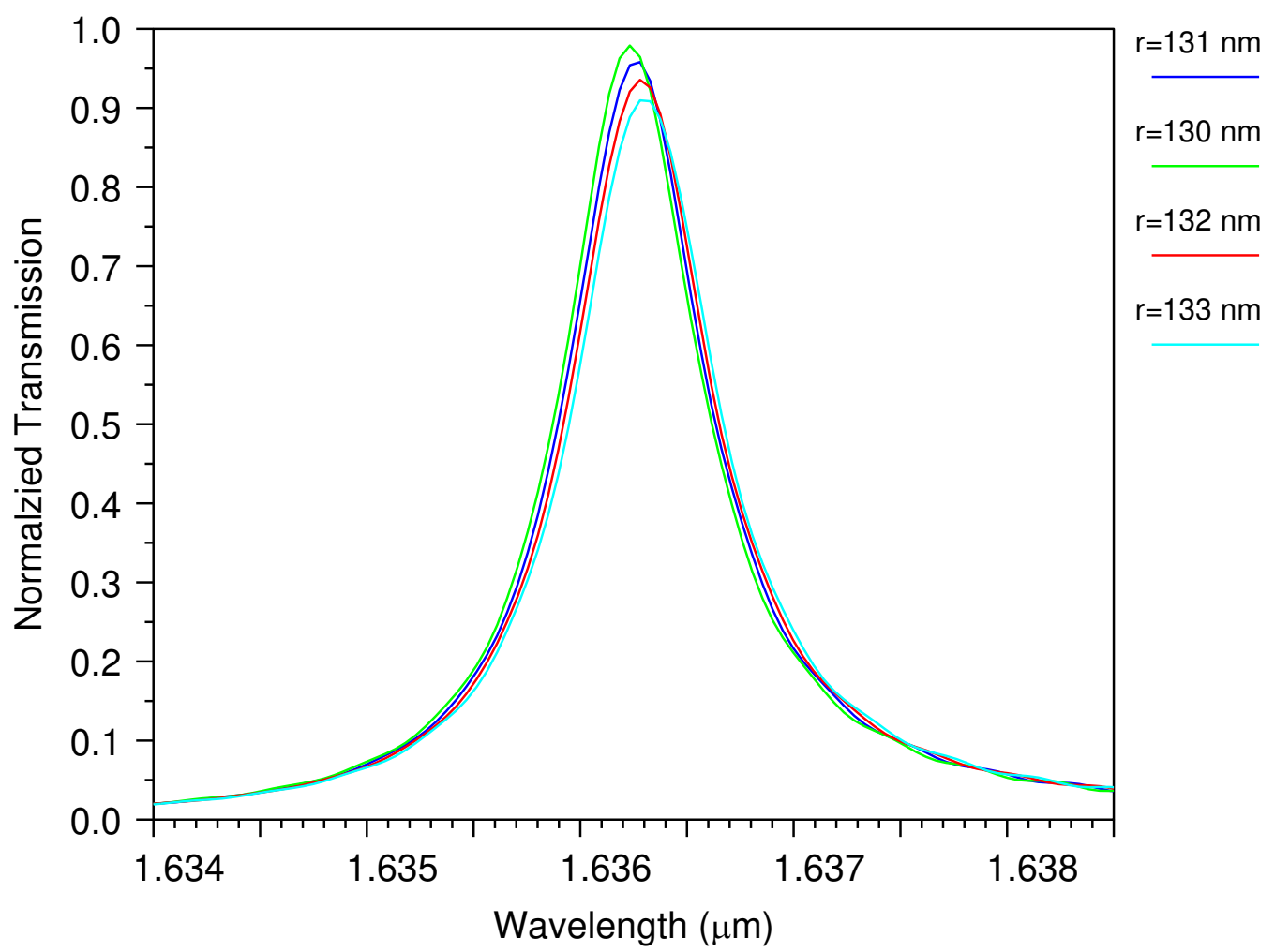

Fig.14. Output spectrum for different coupling rod radius

Table4. Performance parameter with the changes of coupling rod radius (R1) with performance parameters like resonant wavelength, normalized transmission, spectral linewidth, and quality factor

\begin{tabular}{|c|c|c|c|c|c|}
\hline S.no & R1 (nm) & $\begin{array}{c}\text { Resonant } \\
\text { Wavelength } \\
(\mathrm{nm})\end{array}$ & $\begin{array}{c}\text { Normalized } \\
\text { Transmission } \\
(\%)\end{array}$ & $\begin{array}{c}\text { Spectral } \\
\text { Linewidth }(\mathrm{nm})\end{array}$ & $\begin{array}{c}\text { Quality } \\
\text { factor }\end{array}$ \\
\hline 1. & 131 & 1636.3 & 95 & 0.8 & 2045 \\
\hline 2. & 132 & 1636.3 & 93 & 0.8 & 2045 \\
\hline 3. & 133 & 1636.3 & 90 & 0.8 & 2045 \\
\hline
\end{tabular}

\subsection{Regular rod radius Tuning}

Sensitivity of the regular rod tuning is measured by the ratio of difference in resonance wavelength by changing in the rod radius of regular rod. The rod Radius varied from $129 \mathrm{~nm}$ to $131 \mathrm{~nm}$ with increment of $0.5 \mathrm{~nm}$, it is observed that resonant wavelength shifting to higher wavelength of $0.6 \mathrm{~nm}$ for increasing of $0.5 \mathrm{~nm}$ rod radius, which is shown Fig.15. It is also observed that abrupt variation in Transmission Efficiency and quality factor, but spectral linewidth remain constant. The sensitivity of Radius 5 rod variation is measured by

$$
\mathrm{S}_{\text {Radius }}=\frac{\Delta \lambda}{\Delta \text { Radius }}=\frac{0.6}{0.5}=1.2 \mathrm{~nm}
$$

The Radius of the regular rod is highly sensitive to resonant wavelength Tuning. The performance parameter of Radius 1 is tabulated in Table 5. 


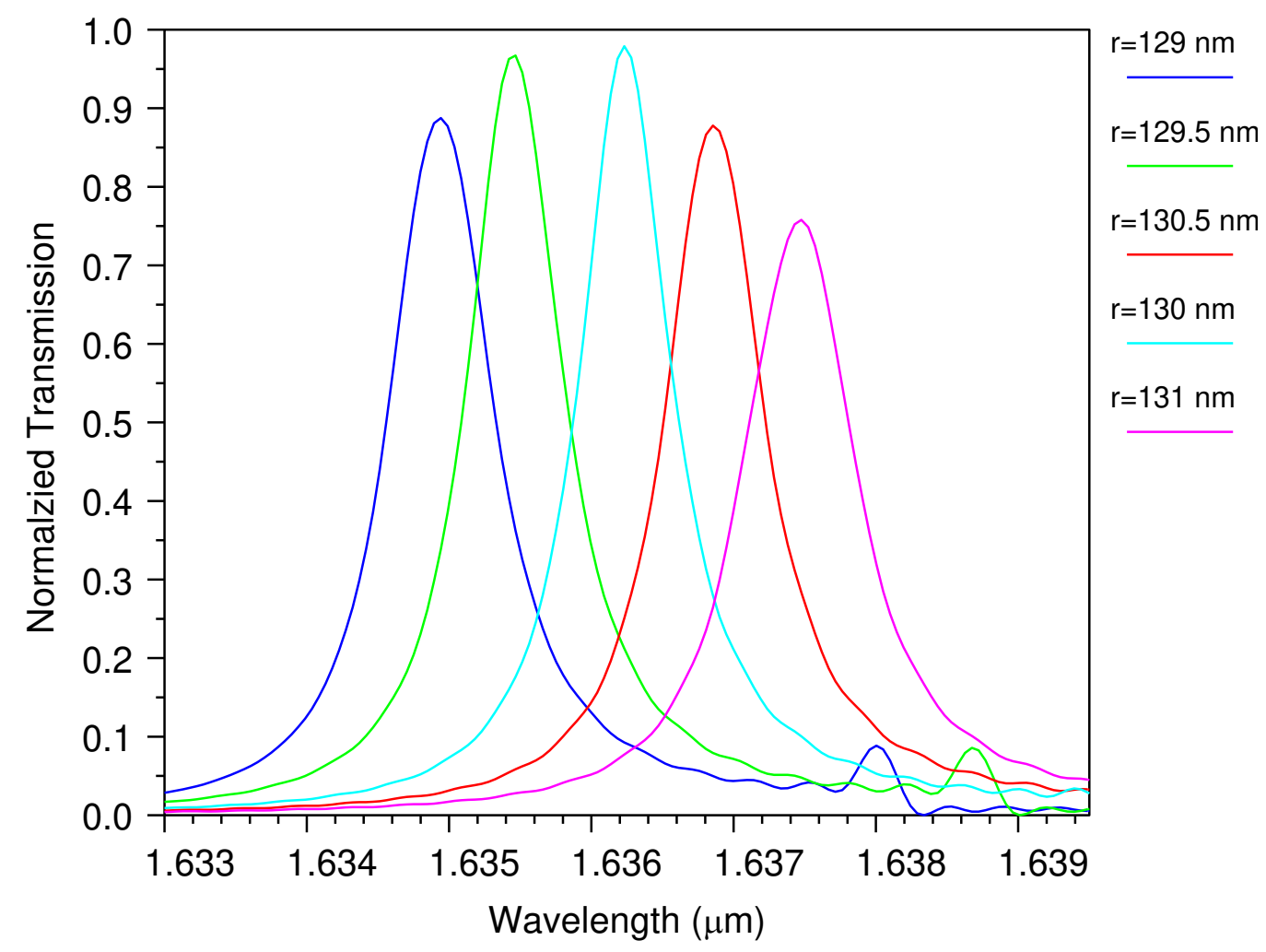

Fig.15. Output spectrum for different coupling rod radius

Table 5. Performance parameter with the changes of regular rod (Radius) with performance parameters like resonant wavelength, normalized transmission, spectral linewidth, and quality factor

\begin{tabular}{|r|c|c|c|c|c|}
\hline S.no & $\begin{array}{c}\text { Radius } \\
(\mathrm{nm})\end{array}$ & $\begin{array}{c}\text { Resonant } \\
\text { Wavelength } \\
(\mathrm{nm})\end{array}$ & $\begin{array}{c}\text { Normalized } \\
\text { Transmission } \\
(\%)\end{array}$ & $\begin{array}{c}\text { Spectral } \\
\text { Linewidth } \\
(\mathrm{nm})\end{array}$ & $\begin{array}{c}\text { Quality } \\
\text { Factor }\end{array}$ \\
\hline 1. & 129 & 1634.9 & 88.7 & 0.9 & 1816 \\
\hline 2. & 129.5 & 1635.5 & 96.3 & 0.8 & 2044 \\
\hline 3. & 130 & 1636 & 99 & 0.8 & 2045 \\
\hline 4. & 130.5 & 1636.9 & 87.66 & 0.8 & 2046 \\
\hline 5. & 131 & 1637.5 & 75.45 & 0.8 & 2046.87 \\
\hline
\end{tabular}

\subsection{Inner rod Tuning}

In $\mathrm{ADF}$, the reference rod radius of the inner quasi ring rod radius (R2) is $130 \mathrm{~nm}$, to measure sensitivity inner rod radius varied from $128 \mathrm{~nm}-131 \mathrm{~nm}$ with the increment of $1 \mathrm{~nm}$ and normalized spectrum is shown in Fig.16. From the results, it is noticed that the abrupt changes in the performance parameter like dropping efficiency, spectral line width, and quality factor.

The performance parameter of ADF with different inner ring rod radius is tabulated in Table 6. However, changing the inner rod radius result in uneven output in the filter; it leads to more changes in transmission efficiency, spectral linewidth, and Q factor. Changing the inner rod radius for tuning mechanism is not feasible in the proposed filter due its uncertainty in the output. 


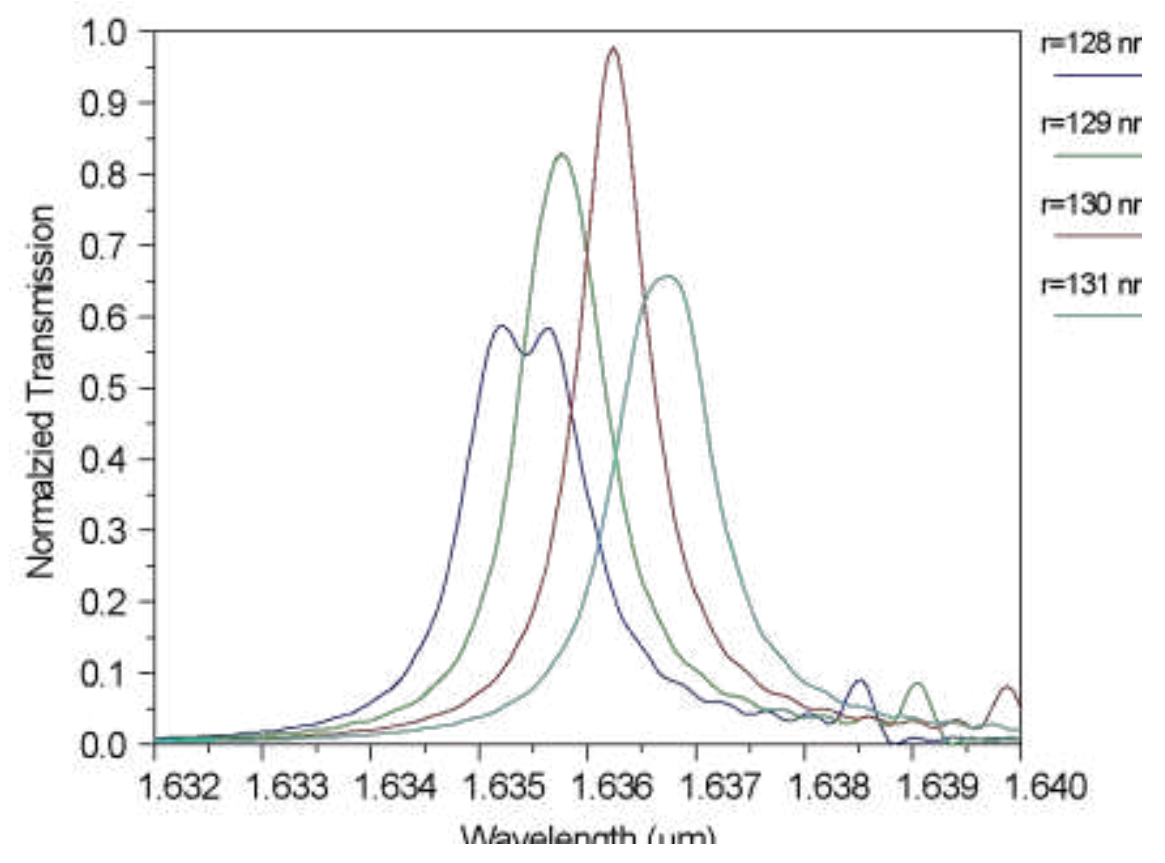

Fig.16. Output spectrum for different inner quasi ring rod radius

Table 6. Performance parameter with the changes of inner quasi ring rod radius with performance parameters like resonant wavelength, normalized transmission, spectral linewidth, and quality factor

\begin{tabular}{|c|c|l|l|l|l|}
\hline S.no & Radius 6 & $\begin{array}{c}\text { Resonant } \\
\text { Wavelength }\end{array}$ & $\begin{array}{c}\text { Normalized } \\
\text { Transmission } \\
(\%)\end{array}$ & $\begin{array}{c}\text { Spectral } \\
\text { Linewidth } \\
(\mathrm{nm})\end{array}$ & $\begin{array}{c}\text { Quality } \\
\text { factor }\end{array}$ \\
\hline 1. & 128 & 1635.2 & 58.5 & 2.1 & 778 \\
\hline 2. & 129 & 1635.8 & 82.6 & 1 & 1635 \\
\hline 3. & 130 & 1636 & 99 & 1 & 1636 \\
\hline 4. & 131 & 1636.8 & 65.6 & 1.1 & 1488 \\
\hline
\end{tabular}

\subsection{Effect of variation in refractive index of rods.}

Tuning to the desired wavelength based on input parameter is important property in $\mathrm{ADF}$. The performance of ADF is validated with change in effect of refractive index variation of adjacent rods, Corner rods, Coupling rods and inner rods.

One row of the adjacent rods, coupling rods, inner rods and corner rods are considered to vary at a time in the value of refractive index, while the other rods value unchanged, in every simulation. The output spectra of our proposed design at port D for different values of refractive index of adjacent rods, coupling rods, inner rods and corner rods shown in Fig.17, Fig.18, Fig.19, and Fig. 20 The output wavelengths shift toward higher wavelengths range, with the refractive index from 3.19 to 3.23 shown in Table 1.The sensitivity of adjacent rods is $0.2 / 0.01$, the shift is accompanied by higher normalized transmission. The sensitivity of corner rods is $0.1 / 0.01$, the shift is noticed with higher normalized transmission. The sensitivity of coupling rods and inner rods is $0.2 / 0.01$, while varying the refractive index in inner rods and coupling rods trivial decrement in transmission efficiency. 


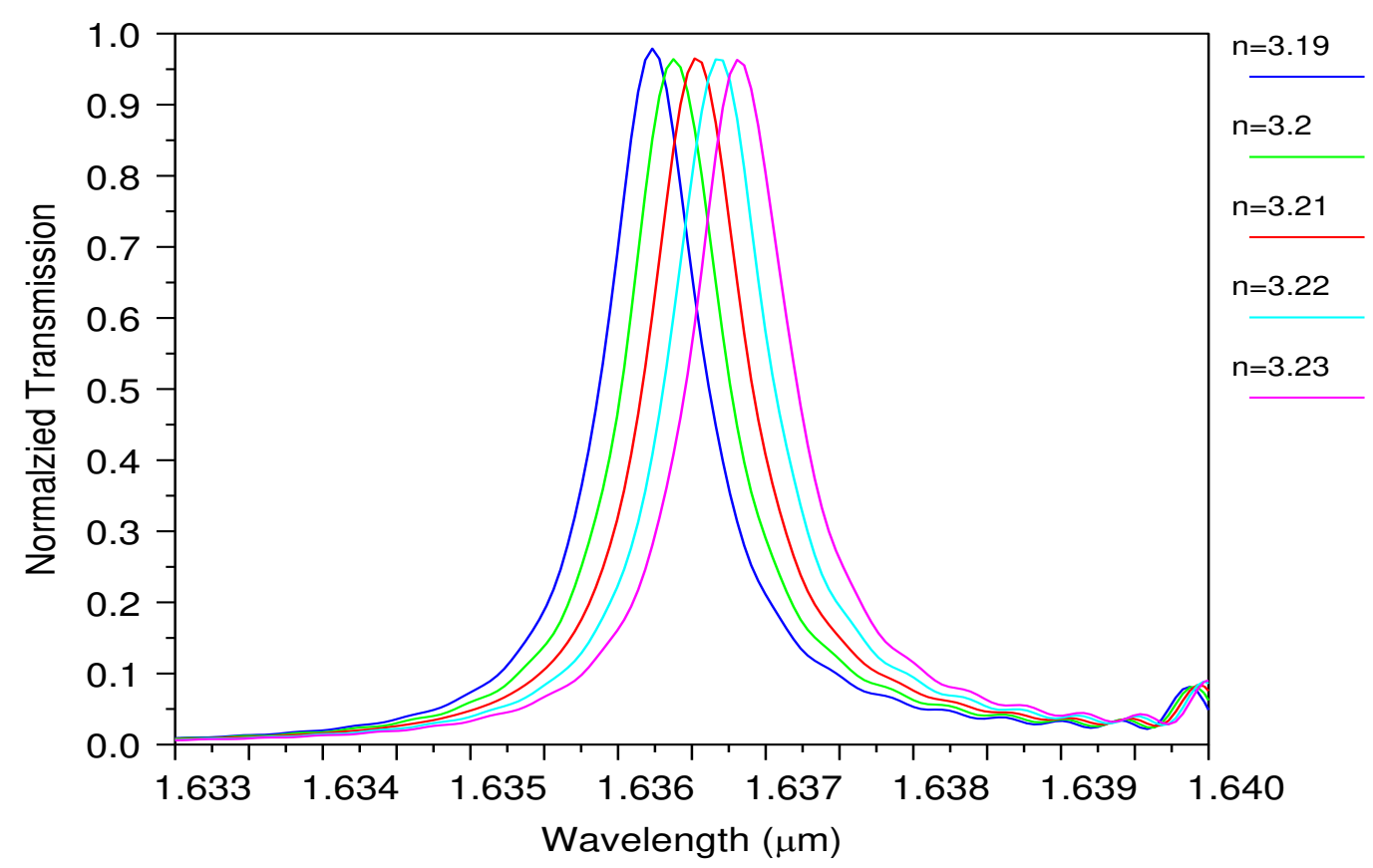

Fig.17. Output spectra of our proposed design for different values of refractive index of adjacent rods

Table 7. Performance parameter with the changes of refractive index of adjacent rods with performance parameters like resonant wavelength, normalized transmission, spectral linewidth, and quality factor

\begin{tabular}{|c|c|c|c|c|l|}
\hline S.no & $\mathrm{n}$ & $\begin{array}{c}\text { Resonant } \\
\text { Wavelength } \\
(\mathrm{nm})\end{array}$ & $\begin{array}{c}\text { Normalized } \\
\text { Transmission } \\
(\%)\end{array}$ & $\begin{array}{c}\text { Spectral } \\
\text { Linewidth } \\
(\mathrm{nm})\end{array}$ & $\begin{array}{l}\text { Quality } \\
\text { Factor }\end{array}$ \\
\hline 1. & 3.19 & 1636.2 & 98 & 0.8 & 2045.25 \\
\hline 2. & 3.20 & 1636.4 & 96.3 & 0.8 & 2045.5 \\
\hline 3. & 3.21 & 1636.5 & 96.4 & 0.8 & 2045.75 \\
\hline 4. & 3.22 & 1636.7 & 96.2 & 0.8 & 2046.00 \\
\hline 5. & 3.23 & 1636.8 & 96.2 & 0.8 & 2045.25 \\
\hline
\end{tabular}

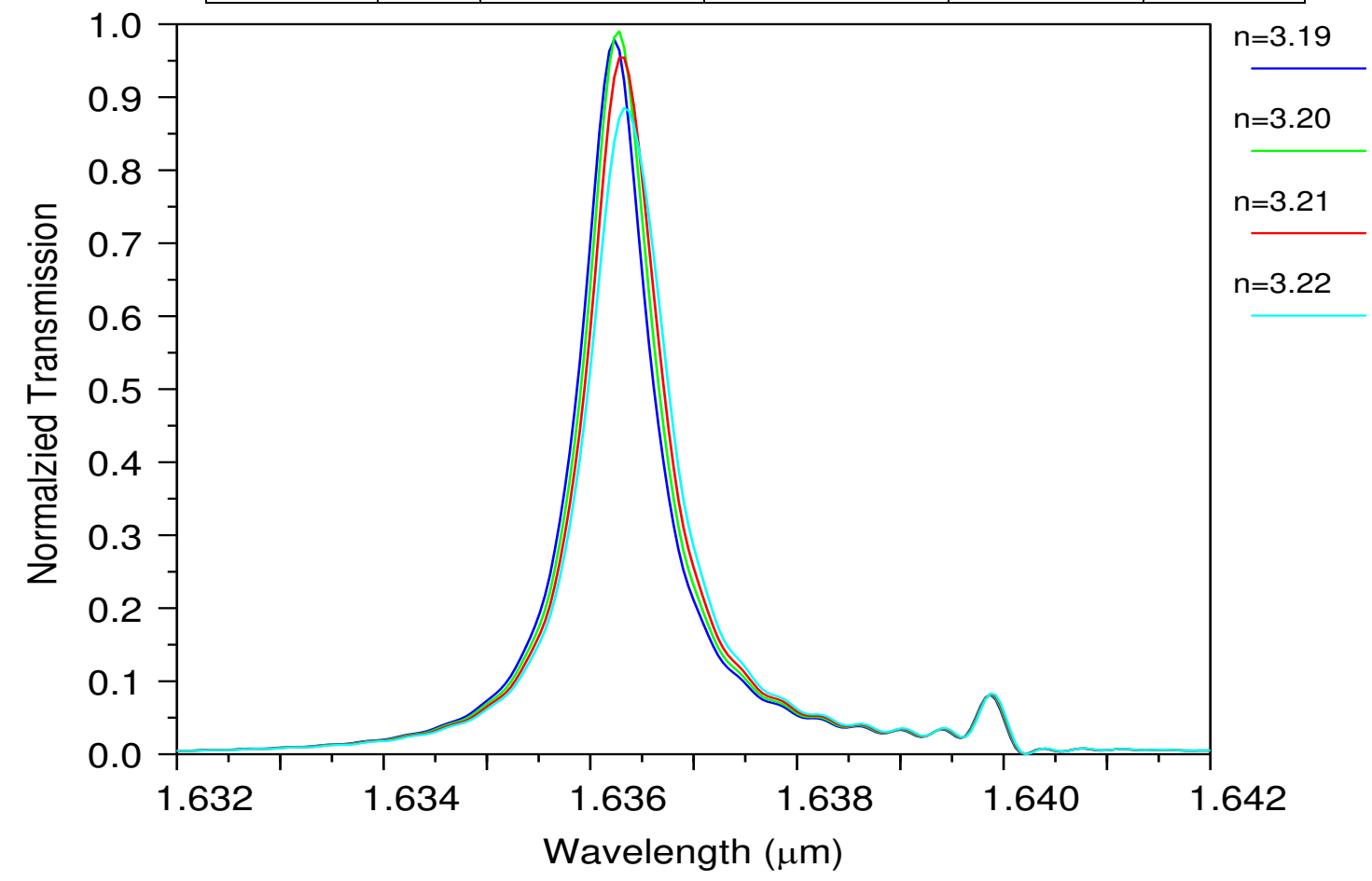


Fig.18. Output spectra of our proposed design for different values of refractive index of corner rods

Table 8. Performance parameter with the changes of refractive index of corner rods with performance parameters like resonant wavelength, normalized transmission, spectral linewidth, and quality factor

\begin{tabular}{|c|c|c|c|c|c|}
\hline S.no & $\mathrm{n}$ & $\begin{array}{c}\text { Resonant } \\
\text { Wavelength } \\
(\mathrm{nm})\end{array}$ & $\begin{array}{c}\text { Normalized } \\
\text { Transmission } \\
(\%)\end{array}$ & $\begin{array}{c}\text { Spectral } \\
\text { Linewidth } \\
(\mathrm{nm})\end{array}$ & $\begin{array}{c}\text { Quality } \\
\text { Factor }\end{array}$ \\
\hline 1. & 3.19 & 1636.2 & 98 & 0.8 & 2045.25 \\
\hline 2. & 3.20 & 1636.3 & 99 & 0.8 & 2045.37 \\
\hline 3. & 3.21 & 1636.3 & 95 & 0.8 & 2045.37 \\
\hline 4. & 3.22 & 1636.3 & 88 & 0.8 & 2045.37 \\
\hline 5. & 3.23 & 1636.4 & 65 & 0.8 & 2045.5 \\
\hline
\end{tabular}

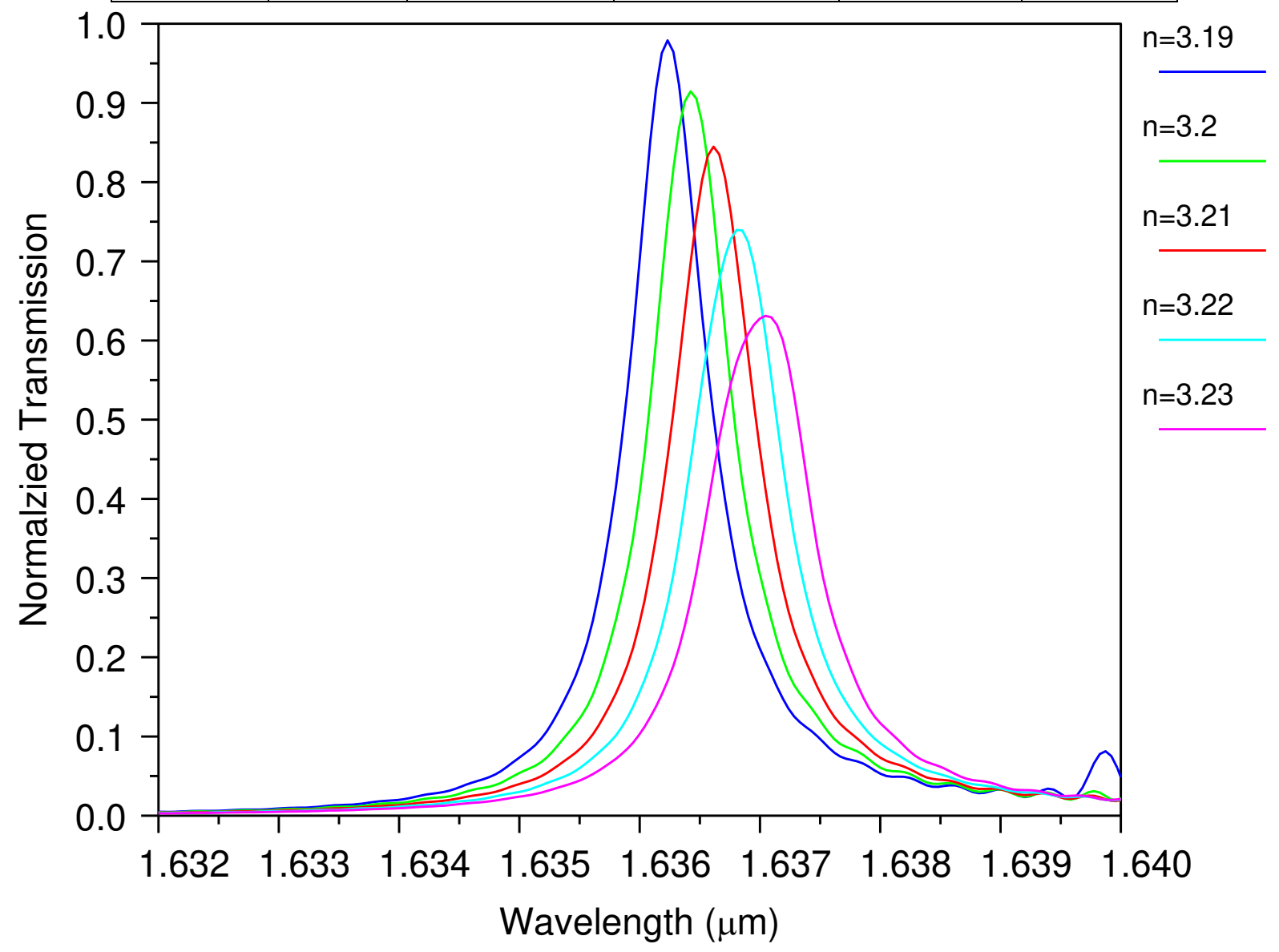

Fig.19. Output spectra of our proposed design for different values of refractive index of coupling rods

Table 9. Performance parameter with the changes of refractive index of coupling rods with performance parameters like resonant wavelength, normalized transmission, spectral linewidth, and quality factor

\begin{tabular}{|r|c|c|c|c|c|}
\hline S.no & $\mathrm{n}$ & $\begin{array}{c}\text { Resonant } \\
\text { Wavelength } \\
(\mathrm{nm})\end{array}$ & $\begin{array}{c}\text { Normalized } \\
\text { Transmission } \\
(\%)\end{array}$ & $\begin{array}{c}\text { Spectral } \\
\text { Linewidth } \\
(\mathrm{nm})\end{array}$ & $\begin{array}{c}\text { Quality } \\
\text { Factor }\end{array}$ \\
\hline 1. 3.19 & 1636.2 & 98 & 0.8 & 2045.25 \\
\hline 2. & 3.2 & 1636.4 & 91 & 0.8 & 2045.50 \\
\hline 3.3 .21 & 1636.6 & 84 & 0.8 & 2045.75 \\
\hline 4. 3.22 & 1636.8 & 74 & 0.8 & 2046.00 \\
\hline
\end{tabular}




\begin{tabular}{|l|l|l|l|l|}
\hline 5.3 .23 & 1637 & 63 & 0.9 & 1815.55 \\
\hline
\end{tabular}

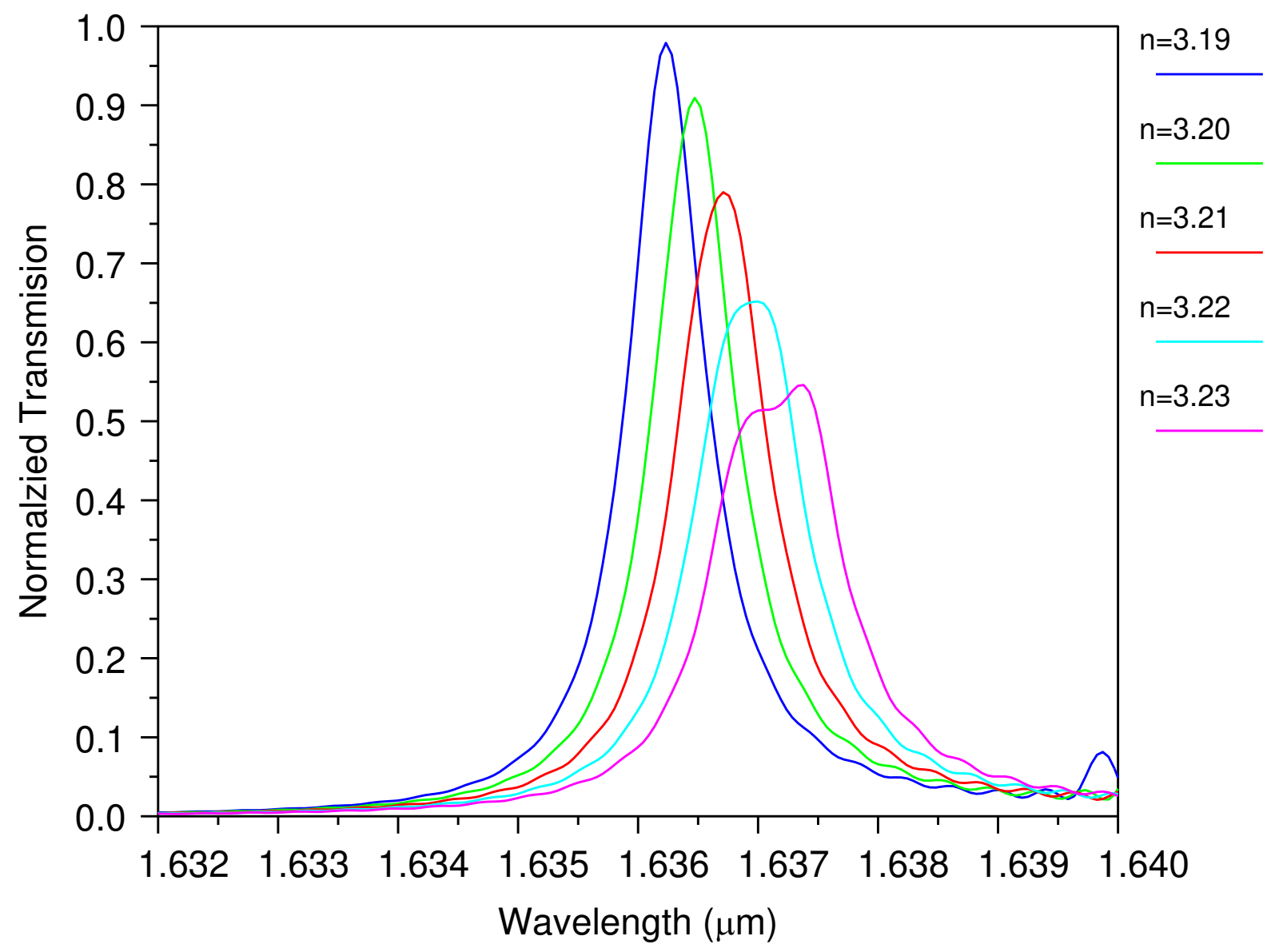

Fig.20 Output spectra of our proposed design for different values of refractive index of inner rods

Table 10.. Performance parameter with the changes of refractive index of inner rods with performance parameters like resonant wavelength, normalized transmission, spectral linewidth, and quality factor

\begin{tabular}{|r|c|c|c|c|c|}
\hline S.no & $\mathrm{n}$ & $\begin{array}{c}\text { Resonant } \\
\text { Wavelength } \\
(\mathrm{nm})\end{array}$ & $\begin{array}{c}\text { Normalized } \\
\text { Transmission } \\
(\%)\end{array}$ & $\begin{array}{c}\text { Spectral } \\
\text { Linewidth } \\
(\mathrm{nm})\end{array}$ & $\begin{array}{c}\text { Quality } \\
\text { Factor }\end{array}$ \\
\hline 1. & 3.19 & 1636.2 & 98 & 0.8 & 2045.25 \\
\hline 2. & 3.2 & 1636.5 & 91 & 0.8 & 2045.62 \\
\hline 3. & 3.21 & 1636.7 & 78 & 0.8 & 2045.87 \\
\hline 4. & 3.22 & 1637 & 65 & 0.9 & 1818.00 \\
\hline 5. & 3.23 & 1637.4 & 54 & 0.9 & 1819.33 \\
\hline
\end{tabular}




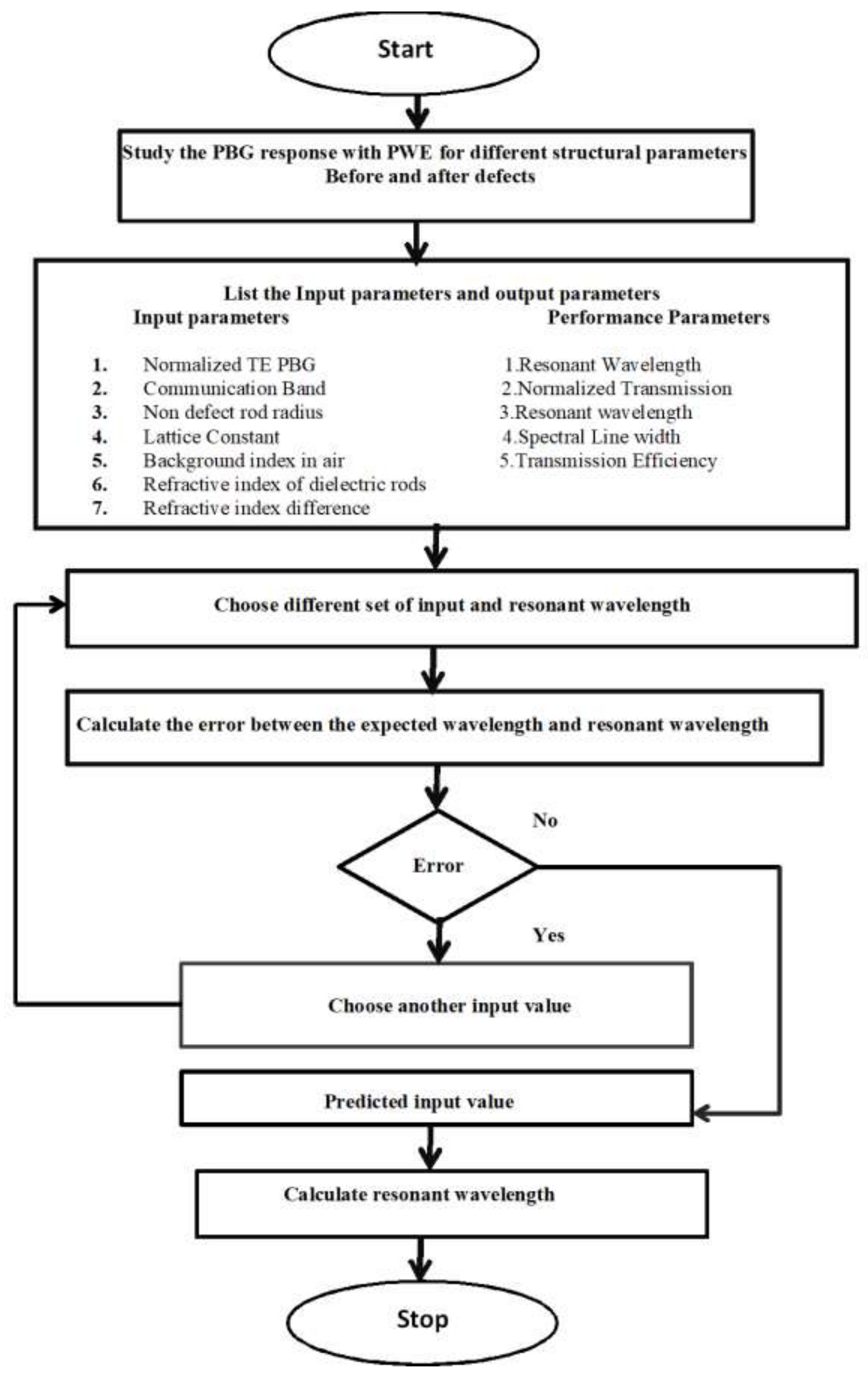

Fig.21. Flowchart of Photonics parameter optimization 
The performance parameter of the proposed design is determined by varying the input parameters for different step increments of input variable and the output spectrum are predicted. Furthermore, the error between the target output value and obtained wavelength is also examined.

The flowchart for the proposed design is shown in Fig. 21. The input variable is incremented with different sets in order to predict the targeted resonant wavelength and to calculate the error between the target wavelength and output wavelength for the different input value. If error exist between target and output value, another input value is to be chosen under iteration to select the optimize rod radii with the lattice constant. If no error then value is predicted and corresponding wavelength is obtained.

The tuning range in the proposed ADF achieved from the range of $1536 \mathrm{~nm}-1637 \mathrm{~nm}$ by varying the one of the structural parameters. The tuning of resonant wavelength for novel rounded square ring resonator is theoretically investigated by altering the structural parameters and the few results are reported here.

1. $1 \mathrm{~nm}$ changes in adjacent rod, $0.3 \mathrm{~nm}$ resonant wavelength is shifted and $0.8 \mathrm{~nm}$ spectral linewidth is observed.

2. $1 \mathrm{~nm}$ changes in scatterer rod, there is $0.1 \mathrm{~nm}$ resonant wavelength is shifted and 0.8 $\mathrm{nm}$ stable spectral linewidth is observed.

3. 1nm changes in coupling rod, resonant wavelength is not shifted from reference wavelength $1636.2 \mathrm{~nm}$.

4. $0.5 \mathrm{~nm}$ changes in regular rod, $0.6 \mathrm{~nm}$ resonant wavelength is shifted from reference wavelength $(1636.2 \mathrm{~nm})$ and stable spectral linewidth is observed.

5. $10 \mathrm{~nm}$ change in lattice constant $25 \mathrm{~nm}$ resonant wavelength shift is observed and spectral linewidth is constant

6. $1 \mathrm{~nm}$ changes in inner quasi ring rods, uncertainty in all performance parameters is observed. 
Table 11. Lattice type, shape of the cavity, backward efficiency, spectral linewidth, device size, refractive index, and resonant wavelength of the proposed ADF is compared with different lattice.

\begin{tabular}{|c|c|c|c|c|c|c|c|}
\hline Reference & Lattice & $\begin{array}{l}\text { Cavity } \\
\text { Shape }\end{array}$ & $\begin{array}{l}\text { Add/ } \\
\text { Drop } \\
(\%)\end{array}$ & $\begin{array}{c}\Delta \lambda \\
)\end{array}$ & $\begin{array}{l}\text { Device } \\
\text { Size } \\
\left(\mu \mathrm{m}^{2}\right)\end{array}$ & $\begin{array}{c}\mathrm{Q} \\
\text { Factor }\end{array}$ & $\Delta n / \lambda_{0}$ \\
\hline Hsiao et al.[15] & \multirow{3}{*}{$\begin{array}{l}\text { Hexago } \\
\text { nal }\end{array}$} & $\begin{array}{l}\text { Hexagon } \\
\text { al }\end{array}$ & 55 & 4 & - & 423 & $3.46 / 1564$ \\
\hline Mahmoud.et.al.[16] & & X shape & 100 & 4 & - & 377 & $3.46 / 1550$ \\
\hline Rajasekar.et.al[17] & & $\begin{array}{l}\text { Trapezoi } \\
\mathrm{d}\end{array}$ & 100 & 3 & 117.6 & 514 & $3.46 / 1543$ \\
\hline $\begin{array}{l}\text { Sathyadevaki.et.al.[1 } \\
8]\end{array}$ & \multirow{10}{*}{ Square } & Square & 35 & 3.5 & 280 & 437 & $3.46 / 1558$ \\
\hline Qiang.et.al.[19] & & \multirow{2}{*}{$\begin{array}{l}\text { Quasi } \\
\text { square }\end{array}$} & 90 & 4 & 242.4 & 387 & $3.46 / 1531$ \\
\hline Alipour.et.al.[20] & & & 96 & 9.8 & - & 160 & $3.59 / 1551$ \\
\hline Robinson.et.al.[21] & & Circular & 89 & 3.5 & 173.42 & 399 & $4 / 1489$ \\
\hline Rezaee.et.al.[22] & & H shape & 100 & 7 & - & 221 & $4.1 / 1550$ \\
\hline Rashki.et.al.[23] & & Flower & 100 & 8 & 152.76 & 205.5 & $3.46 / 1644$ \\
\hline Chhipa.et.al.[24] & & $\begin{array}{c}\text { Curved } \\
\text { Fabry } \\
\text { Perot }\end{array}$ & 99 & 13 & 123 & 194 & $3.40 / 1511$ \\
\hline Alipour.et.al.[25] & & $\begin{array}{c}\text { Elliptical } \\
\text { resonant } \\
\text { ring }\end{array}$ & 100 & 2 & - & 647 & $4.2 / 1555$ \\
\hline Radhouene.et.al.[26] & & $\begin{array}{l}\text { Square } \\
\text { ring } \\
\text { (Super } \\
\text { elliptic } \\
\text { inner } \\
\text { ring }\end{array}$ & 92 & 0.7 & - & 2210 & $3.19 / 1547.3$ \\
\hline Proposed Work & & $\begin{array}{c}\text { Square(I } \\
\text { nner } \\
\text { quasi } \\
\text { ring) }\end{array}$ & $>98$ & 0.7 & 412.76 & 2337 & $3.19 / 1636.2$ \\
\hline
\end{tabular}

$\eta$ - Backward drop efficiency Q-quality factor $\quad \lambda_{0}$-Strong resonant wavelength
$\Delta \lambda$ Spectral line width
$\Delta$-Delta

The functional parameters of the filter like lattice, cavity design, backdrop efficiency, spectral linewidth, device size, quality factor, refractive index, and resonant wavelength are compared with reported Add Drop filter is tabulated in Table 7. From the reported paper, the existing Add Drop filter design with low quality factor for the backward drop wavelength is replaced with high quality factor to support WDM systems and functional parameters also significantly enhanced compared to reported paper and hence proposed design can be implemented for Photonic Integrated Circuits. 


\section{Conclusion}

The proposed single ADF design with novel Rounded Square Ring Resonator to support the WDM system to drop the strong resonant wavelength of $1636.2 \mathrm{~nm}$ was designed. The novelty in the proposed drop filter is to drop the desired wavelength with globalized defect rod radius for full design and new shape. The spectral line width of backdrop wavelength is $0.7 \mathrm{~nm}$ and quality factor 2337 and $>98$ transmission efficiency respectively. We investigate the effect of structural parameter with resonant wavelength for the proposed structure and also the best structural parameter for the tuning mechanism is reported. Compared to existing works this drop filter drop the high narrow band backward drop wavelength to support DWDM applications also proposed filter chip area is $412.76 \mu \mathrm{m}^{2}$. Hence proposed drop filter suitable for the implementation of Photonic Integrated Circuits (PIC) for DWDM applications. In future, this proposed design enhances the drop spectral linewidth to $0.4 \mathrm{~nm} / 0.2 / 0.1 \mathrm{~nm}$ to support DWDM systems by increasing the rod between the waveguide and cavity.

\section{References}

Tran, A. T. T. D., Lo, Y. H., Zhu, Z. H., Haronian, D., Mozdy, E.: Surface micromachined Fabry-Perot tunable filter. IEEE Photonics Technol. Lett., 8(3), 393(1996).

Kersey, A.D., Berkoff, T.A.,Morey, W.W.:Multiplexed fiber Bragg grating strainsensor system with a fiber Fabry-Perot wavelength filter, Opt. Lett., 18 (16), 1370(1993).

Wooten, E.L., Stone, R.L., Miles, E.W.,Bradley, E.M.:Rapidly tunable narrowband wavelength filter using $\mathrm{LiNbO} /$ sub 3/unbalanced Mach-Zehnder interferometers, $\mathrm{J}$. Light. Technol., 14(11), 2530(1996).

Sun, S.: A dual-band bandpass filter using a single dual-mode ring resonator. IEEE Microw. Wirel. Compon. Lett., 21(6), 298(2011).

Joannopoulos, J.D., Villeneuve, P.R., Fan, S.: Photonic crystals. Solid State Communications, 102(2-3), 65(1997).

Meier, M., Mekis, A., Dodabalapur, A., Timko, A., Slusher, R.E., Joannopoulos, J.D. Nalamasu, O.:Laser action from two-dimensional distributed feedback in photonic crystals. Applied Physics Letters, 74(1), 7(1999).

Fan, S., Villeneuve, P.R., Joannopoulos, J.D., Haus, H.A.: Channel drop filters in photonic crystals. Opt. Express, 3(1), 4(1998).

Fenzl, C., Hirsch, T., Wolfbeis, O.S.: Photonic crystals for chemical sensing and biosensing, Angew. Chem. Int., 53(13), 3318(2014). 
Balaji, V.R., Murugan, M., Robinson, S.: Optimization of DWDM demultiplexer using regression analysis, J. Nanomater. 1(2016).

Zhang, Y., Zhang, Y., Li, B.: Optical switches and logic gates based on self-collimated beams in two-dimensional photonic crystals, Opt. Express, 15(15), 9287(2007).

Mehdizadeh, F., Soroosh, M.,Alipour-Banaei, H.:Proposal for 4-to-2 optical encoder based on photonic crystals, IET Optoelectron., 11(1), 29(2016).

Beggs, D.M., White, T.P., O'Faolain, L.,Krauss, T.F.:Ultracompact and low-power optical switch based on silicon photonic crystals, Opt. Lett., 33 (2), 147(2008).

Jiang, Y., Jiang, W., Gu, L., Chen, X.,Chen, R.T.:80-micron interaction length silicon photonic crystal waveguide modulator, Appl. Phys. Lett., 87(22), 221105(2005).

Joannopoulos, J.D., Villeneuve, P.R,Fan, S.: Photonic crystals: putting a new twist on light, Nature, 386(6621), 143(1997).

Hsiao, F.L.,Lee, C.:A nano-ring resonator based on 2-D hexagonal-lattice photonic crystals. In 2009 IEEE/LEOS International Conference on Optical MEMS and Nanophotonics, 107 (2009).

Mahmoud, M.Y., Bassou, G., Taalbi, A.,Chekroun, Z.M.:Optical channel drop filters based on photonic crystal ring resonators, Opt. Commun. 285 (3), 368(2012).

Rajasekar, R.,Robinson, S.:Trapezoid 2D photonic crystal nanoring resonator-based channel drop filter for WDM systems, Photonic Netw. Commun., 36(2), 230(2018).

Sathyadevaki, R., Raja, A.S.: Photonic crystal-based optical filter: a brief investigation, Photonic Netw. Commun., 33(1), 77(2017).

Qiang, Z., Zhou, W.,Soref, R.A.:Optical add-drop filters based on photonic crystal ring resonators, Opt. Express, 15(4), 1823(2007).

Alipour-Banaei, H., Jahanara, M., Mehdizadeh, F.: T-shaped channel drop filter based on photonic crystal ring resonator, Optik, 125(18).5348(2014).

Robinson, S.,Nakkeeran, R.:Two dimensional photonic crystal ring resonator based add drop filter for CWDM systems, Optik, 124(18), 3430(2018).

Rezaee, S., Zavvari,,Alipour-Banaei, H.:A novel optical filter based on H-shape photonic crystal ring resonators, Optik, 126(20), 2535(2015).

Rashki, Z., Chabok, S.J.S.M.:Novel design of optical channel drop filters based on two-dimensional photonic crystal ring resonators, Opt. Commun., 395, 231(2017). 
Chhipa, M.K., Radhouene, M., Dikshit, A., Robinson, S., Suthar, B.: Novel compact optical channel drop filter for CWDM optical network applications, Int. J. Photonics Opt. Technol, 2(4), 26(2016).

Alipour-Banaei, H., Mehdizadeh, F., Hassangholizadeh-Kashtiban, M.: A new proposal for PCRR-based channel drop filter using elliptical rings, Physica E Low Dimens. Syst. Nanostruct., 56, 211(2014).

Massoudi, R., Najjar, M., Mehdizadeh, F., Janyani, V.: Investigation of resonant mode sensitivity in PhC based ring resonators, Opt. Quantum Electron, 51(3), 87(2019).

Fan, S., Wang, Z., Miller, D.A., Villeneuve, P.R., Haus, H.A.,Joannopoulos, J.D. :Photonic crystal for communication applications. In Active and Passive Optical Components for WDM Communications II, 4870, 339(2002).

Shi, S., Chen, C.,Prather, D.W.:Plane-wave expansion method for calculating band structure of photonic crystal slabs with perfectly matched layers, J. Opt. Soc. Am. A., 21(9), 1769(2004).

Qiu, M.: Analysis of guided modes in photonic crystal fibers using the finitedifference time-domain method, Microw. Opt. Technol. Lett., 30(5), 327(2001).

Park, S.J., Lee, C.H., Jeong, K.T., Park, H.J., Ahn, J.G., Song, K.H.: Fiber-to-thehome services based on wavelength-division-multiplexing passive optical network, J.Light.Technol., 22 (11), 2582(2004).

Chew, W.C., Liu, Q.H.: Perfectly matched layers for elastodynamics: a new absorbing boundary condition, J. Theor. Comput. Acoust., 4(04), 341(1996).

Xiao, S., Vahldieck, R.:An efficient 2-D FDTD algorithm using real variables (guided wave structure analysis), IEEE Microw. Wirel. Compon. Lett., 3(5), pp.127 (1993).

Ohteru, S., Takachio, N.,Optical signal quality monitor using direct Q-factor measurement, IEEE Photon. Technol. Lett., 11(10), 1307(1999).

Shahidinejad, A.: Soliton Pulse Generation for WDM-Based Free Space Optics Communication Using Microring Resonators, J. Opt. Commun., 25(1),59-64(2018).

Rayleigh, L.: XVII. On the maintenance of vibrations by forces of double frequency, and on the propagation of waves through a medium endowed with a periodic structure, Philos. Mag., 24(147), 145-159(1887). 


\section{Figure Caption}

1. Fig.1 PBG before introducing the defects

2. Fig.2 Effects of normalized frequency with respect to the rod radius

3. Fig.3 Effects of normalized frequency with respect to the lattice constant (Period)

4. Fig.4 Effects of normalized frequency with respect to the refractive index difference (delta)

5. Fig.5 Band gap diagram after introducing line and point defects

6. Fig.6. Schematic representation of WDM network with Add Drop Filter

7. Fig.7 ADF response at (a) ON state (b) OFF state

8. Fig.8 Proposed Rounded Square Ring resonator based Add Drop filter

9. Fig.9 Normalized output spectrum of the proposed Add Drop filter

10. Fig.10 Electric field distribution of the proposed Add Drop filter at (a) ON resonance $(1636.2 \mathrm{~nm})$ and (b) OFF resonance $(1633 \mathrm{~nm})$

11. Fig.11 Output spectrum for different lattice constant

12. Fig.12 Effect of change of output spectrum adjacent rod radius

13. Fig.13 Output spectrum for different scattered rod radius

14. Fig.14 Output spectrum for different coupling rod radius

15. Fig.15. Output spectrum for different coupling rod radius

16. Fig.16 Output spectrum for different inner quasi ring rod radius

17. Fig.17. Output spectra of our proposed design for different values of refractive index of adjacent rods

18. Fig.18. Output spectra of our proposed design for different values of refractive index of corner rods

19. Fig.19. Output spectra of our proposed design for different values of refractive index of coupling rods

20. Fig.20 Output spectra of our proposed design for different values of refractive index of inner rods

21. Fig.21. Flowchart of Photonics parameter optimization 


\section{Table Caption}

Table 1. Performance parameter with the changes of Lattice constant (a) with performance parameters like resonant wavelength, normalized transmission, spectral linewidth, and quality factor

Table 2. Performance parameter with the changes of adjacent rod radius (R4) with performance parameters like resonant wavelength, normalized transmission, spectral line width, and quality factor

Table 3. Functional parameter with the changes of Scatterer rod radius (R3) with performance parameters like resonant wavelength, normalized transmission, spectral linewidth, and quality factor

Table 4. Performance parameter with the changes of coupling rod radius (R1) with performance parameters like resonant wavelength, normalized transmission, spectral linewidth, and quality factor

Table 5. .Performance parameter with the changes of regular rod (Radius) with performance parameters like resonant wavelength, normalized transmission, spectral linewidth, and quality factor

Table 6. Performance parameter with the changes of inner quasi ring rod radius with performance parameters like resonant wavelength, normalized transmission, spectral linewidth, and quality factor

Table 7. Performance parameter with the changes of refractive index of adjacent rods with performance parameters like resonant wavelength, normalized transmission, spectral linewidth, and quality factor

Table 8. Performance parameter with the changes of refractive index of corner rods with performance parameters like resonant wavelength, normalized transmission, spectral linewidth, and quality factor

Table 9. Performance parameter with the changes of refractive index of coupling rods with performance parameters like resonant wavelength, normalized transmission, spectral linewidth, and quality factor

Table 10.. Performance parameter with the changes of refractive index of inner rods with performance parameters like resonant wavelength, normalized transmission, spectral linewidth, and quality factor

Table 11. Lattice type, shape of the cavity, backward efficiency, spectral linewidth, device size, refractive index, and resonant wavelength of the proposed ADF is compared with different lattice. 

Figures

TE/TM Band Structure

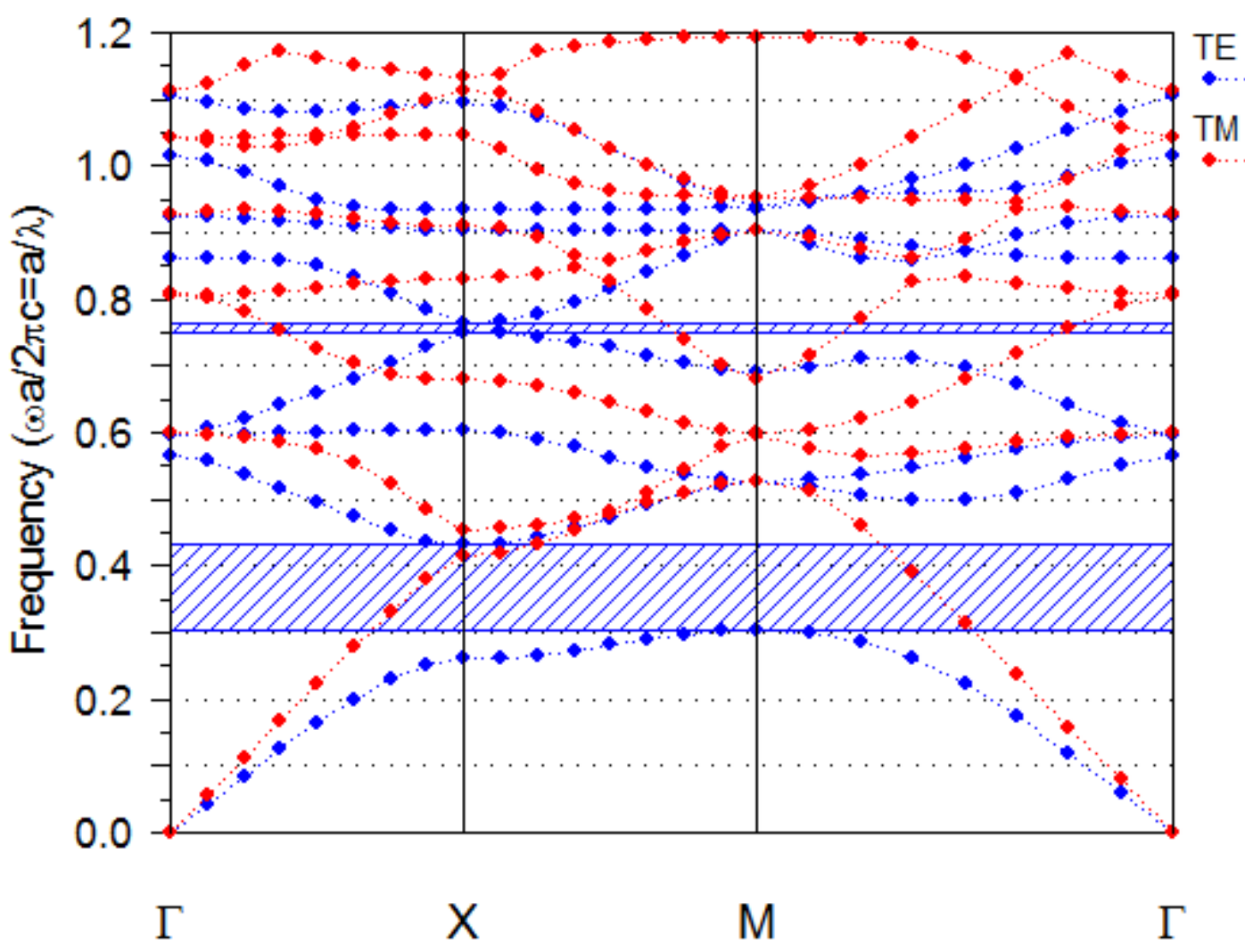

Figure 1

PBG before introducing the defects

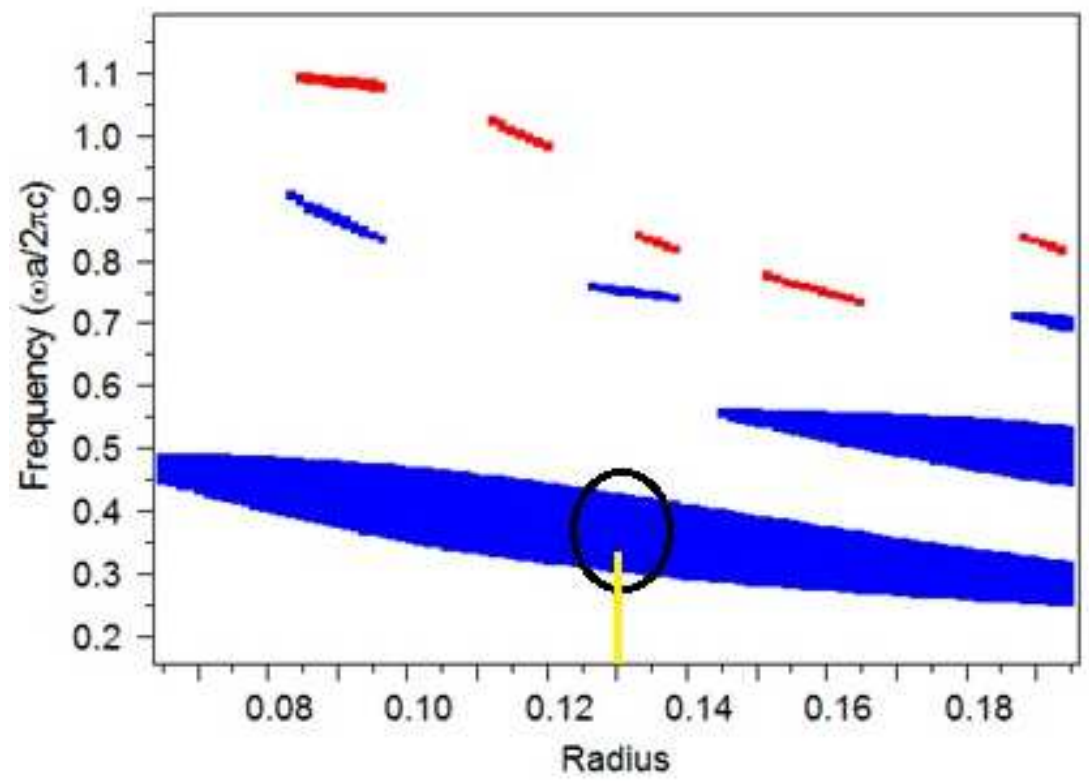


Figure 2

Effects of normalized frequency with respect to the rod radius

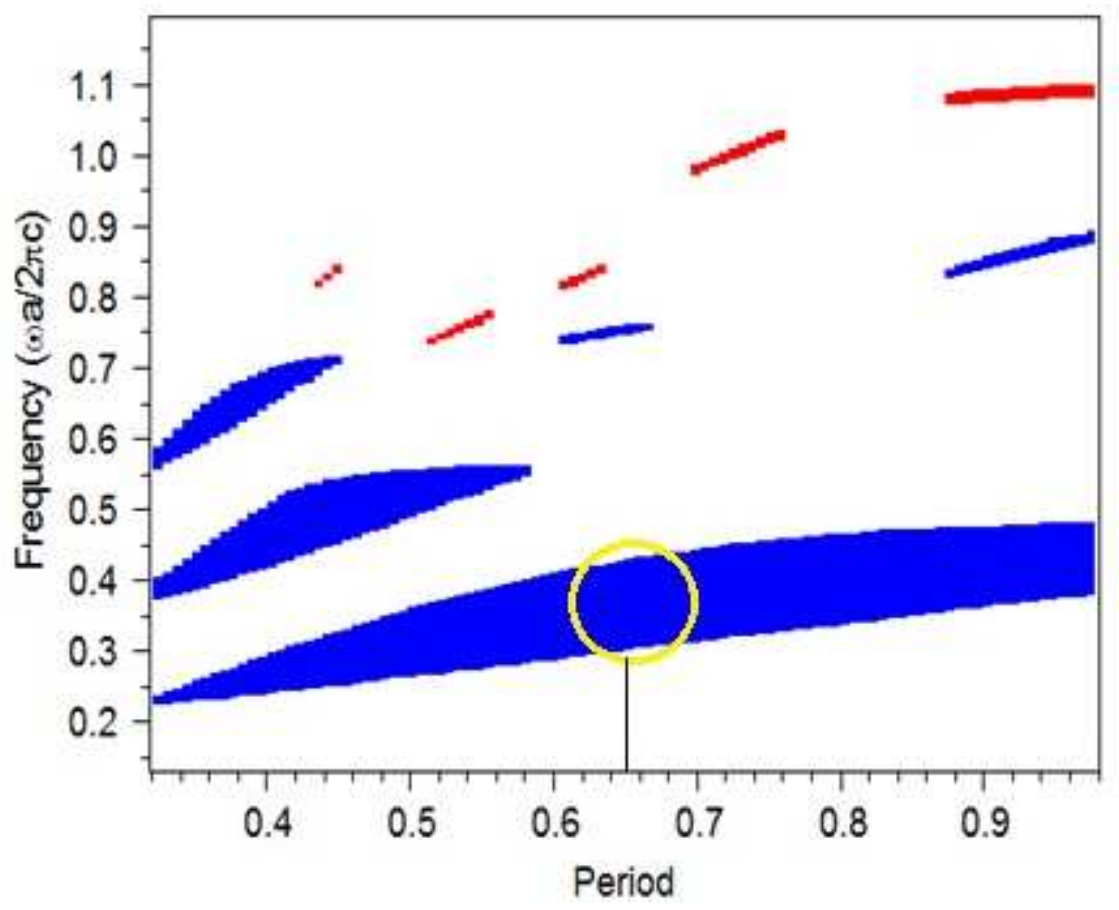

Figure 3

Effects of normalized frequency with respect to the lattice constant (period)

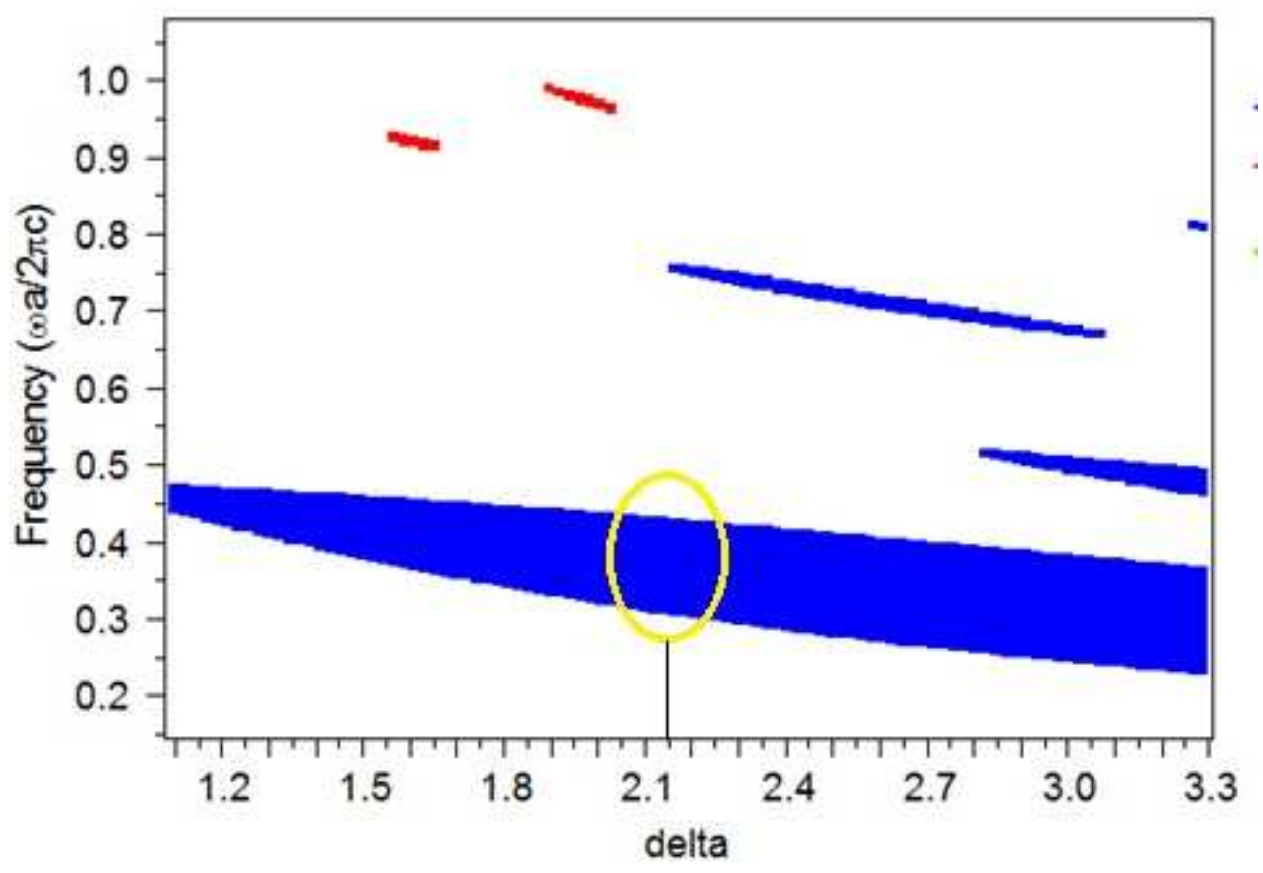

Figure 4

Effects of normalized frequency with respect to the refractive index difference (delta) 


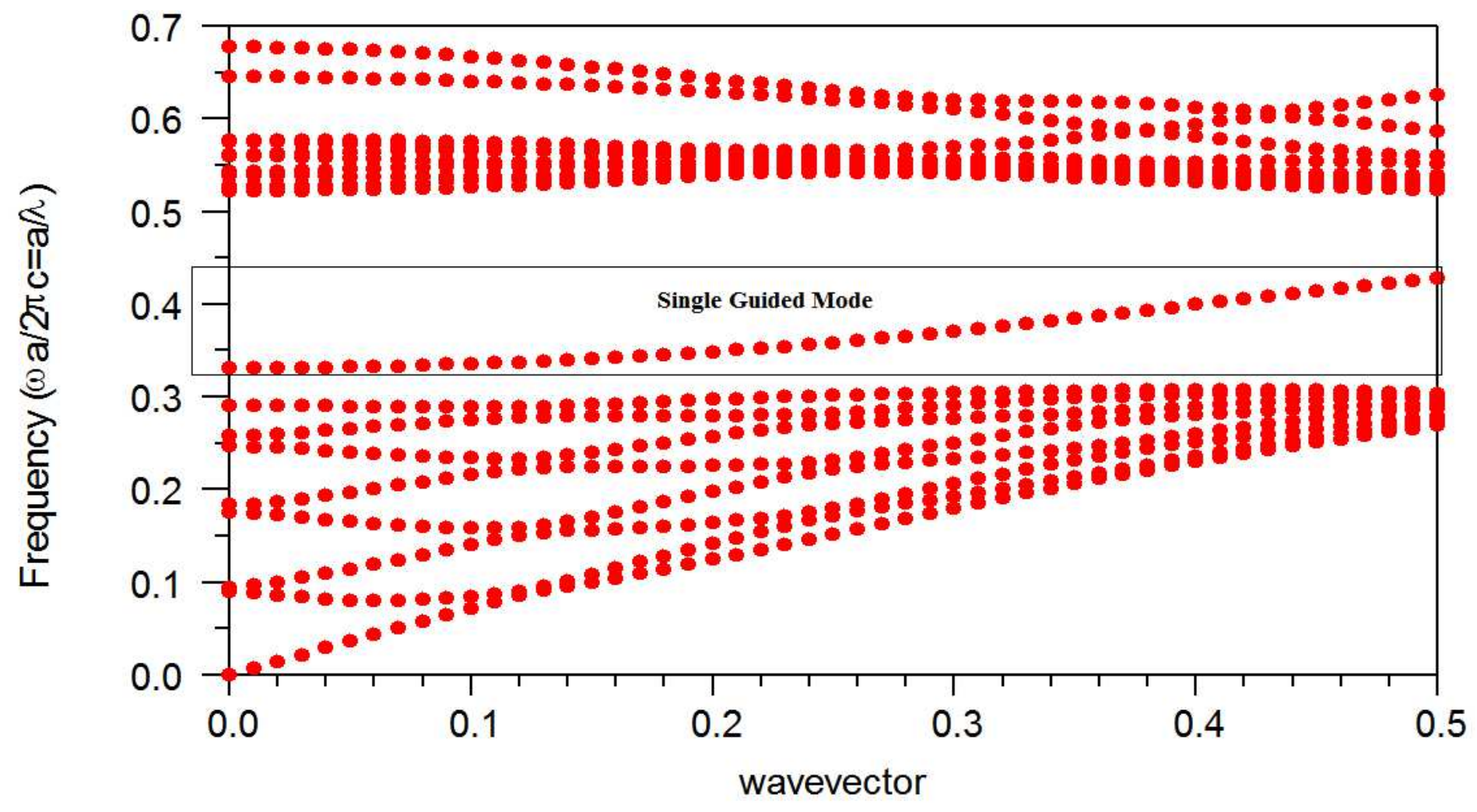

Figure 5

Band gap diagram after introducing line and point defects

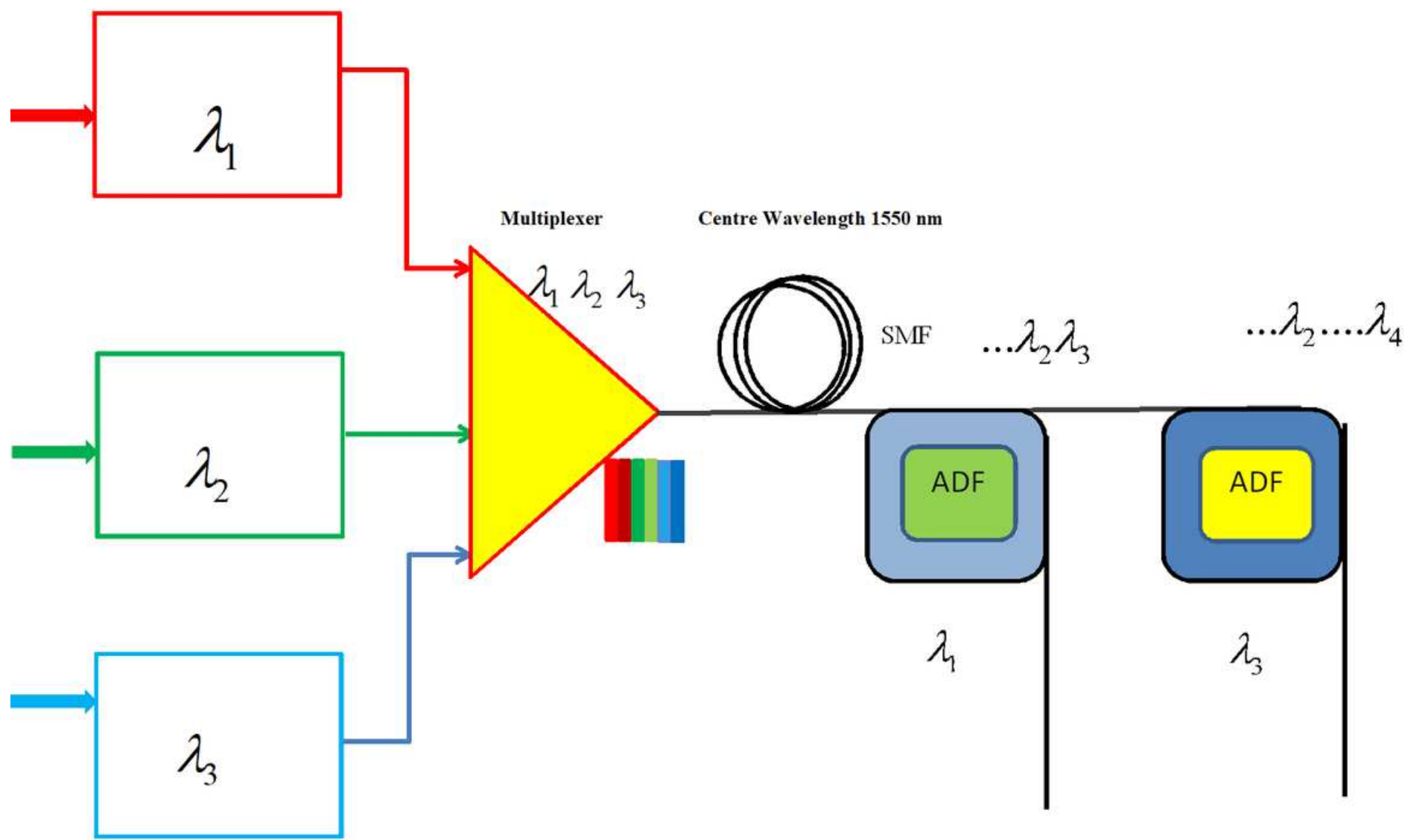


Figure 6

Schematic representation of WDM network with Add Drop Filter

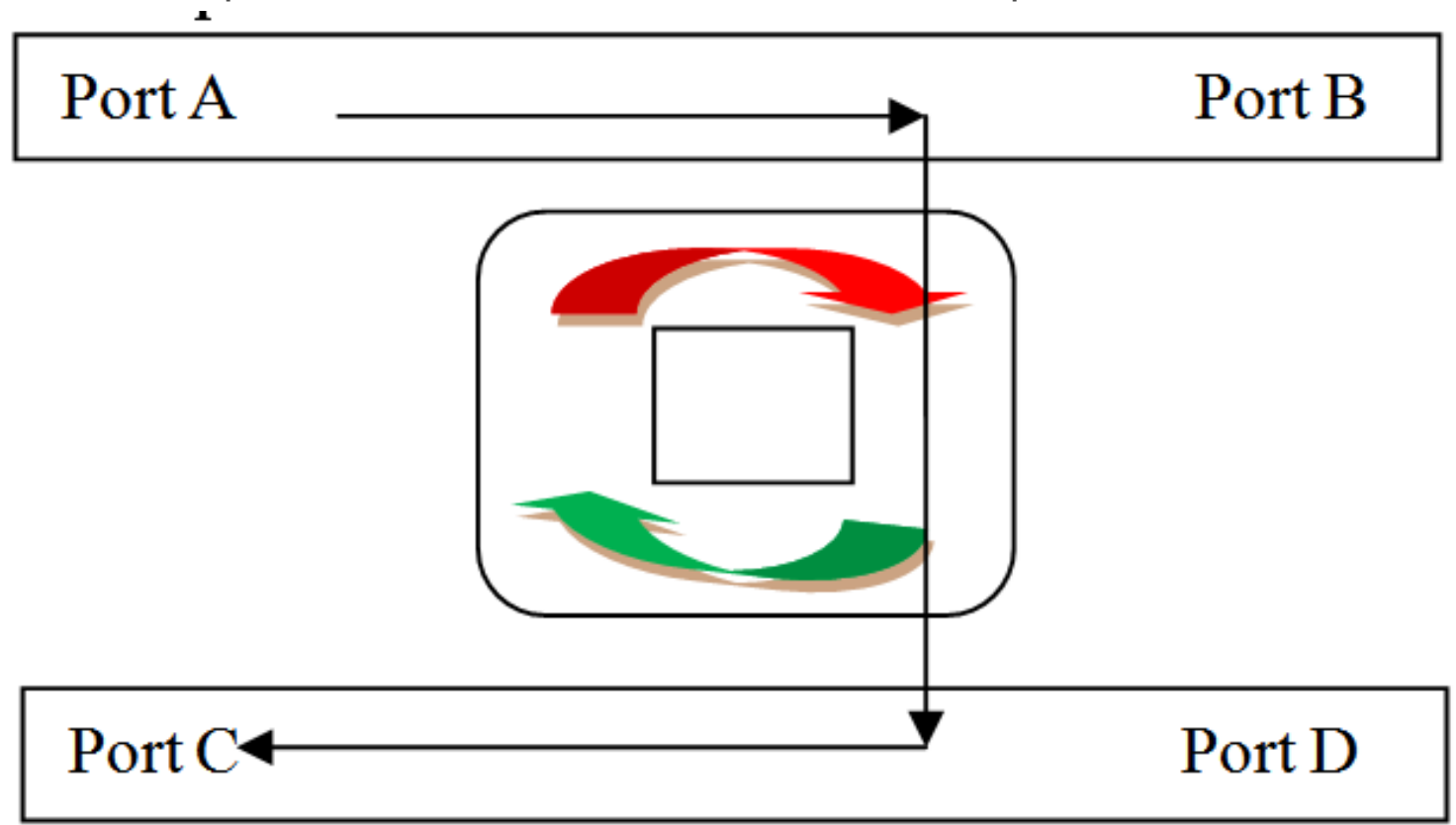

(a)

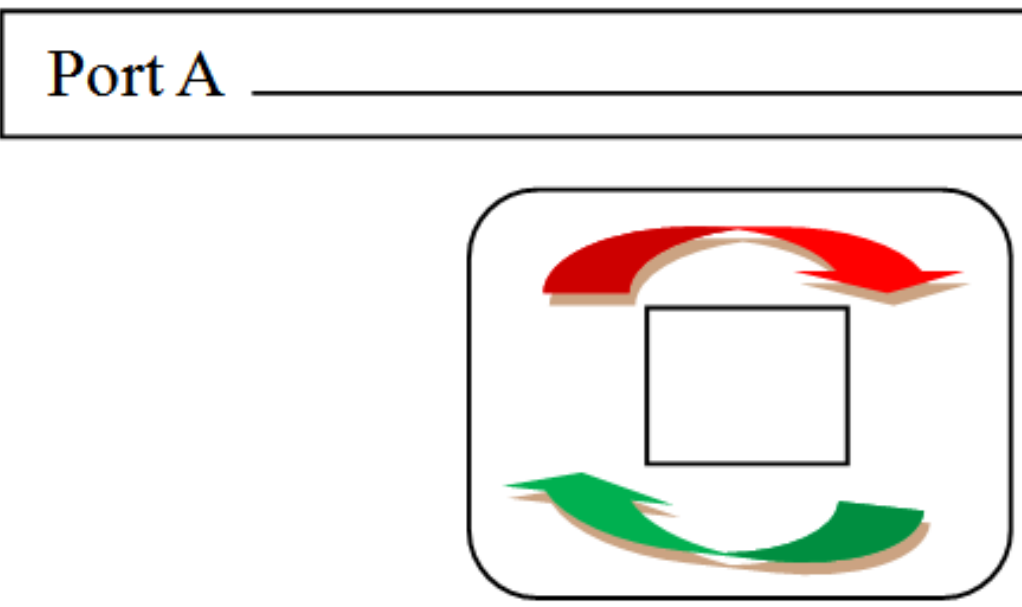

\section{Port C}

Port D

(b)

Figure 7

ADF response at (a) ON state (b) OFF state 


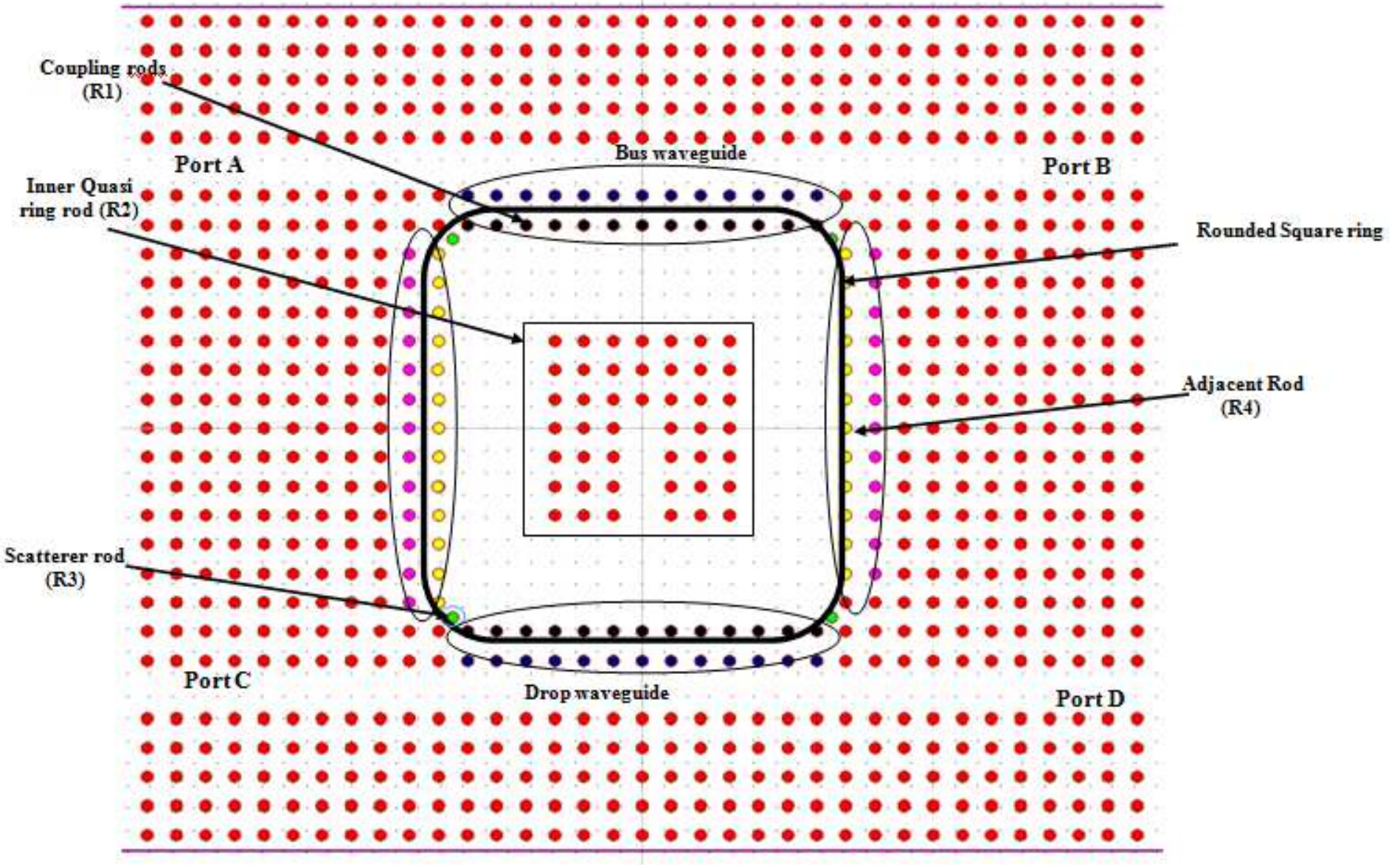

Figure 8

Proposed Rounded Square Ring resonator based Add Drop filter 


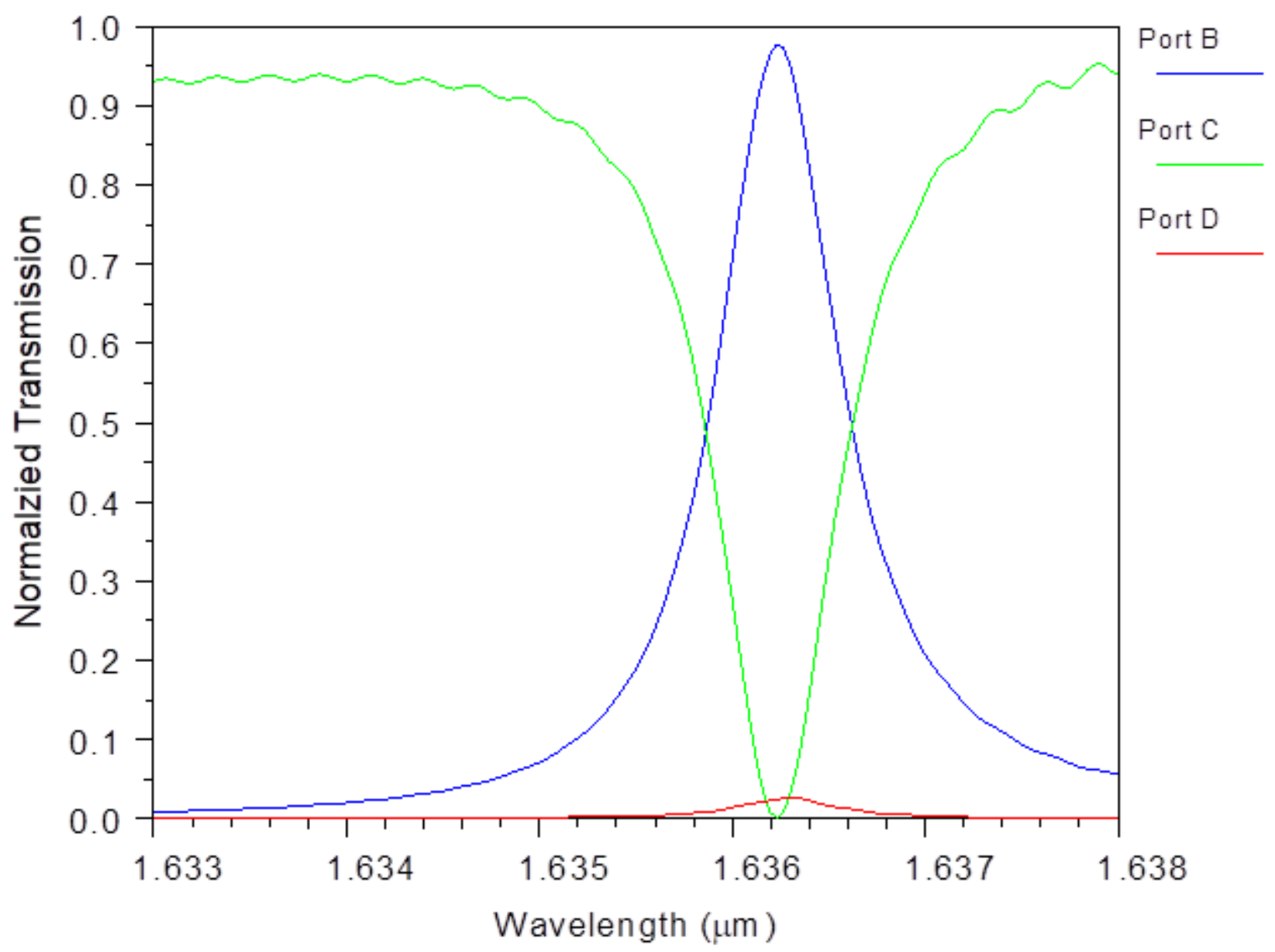

Figure 9

Normalized output spectrum of the proposed Add Drop filter 

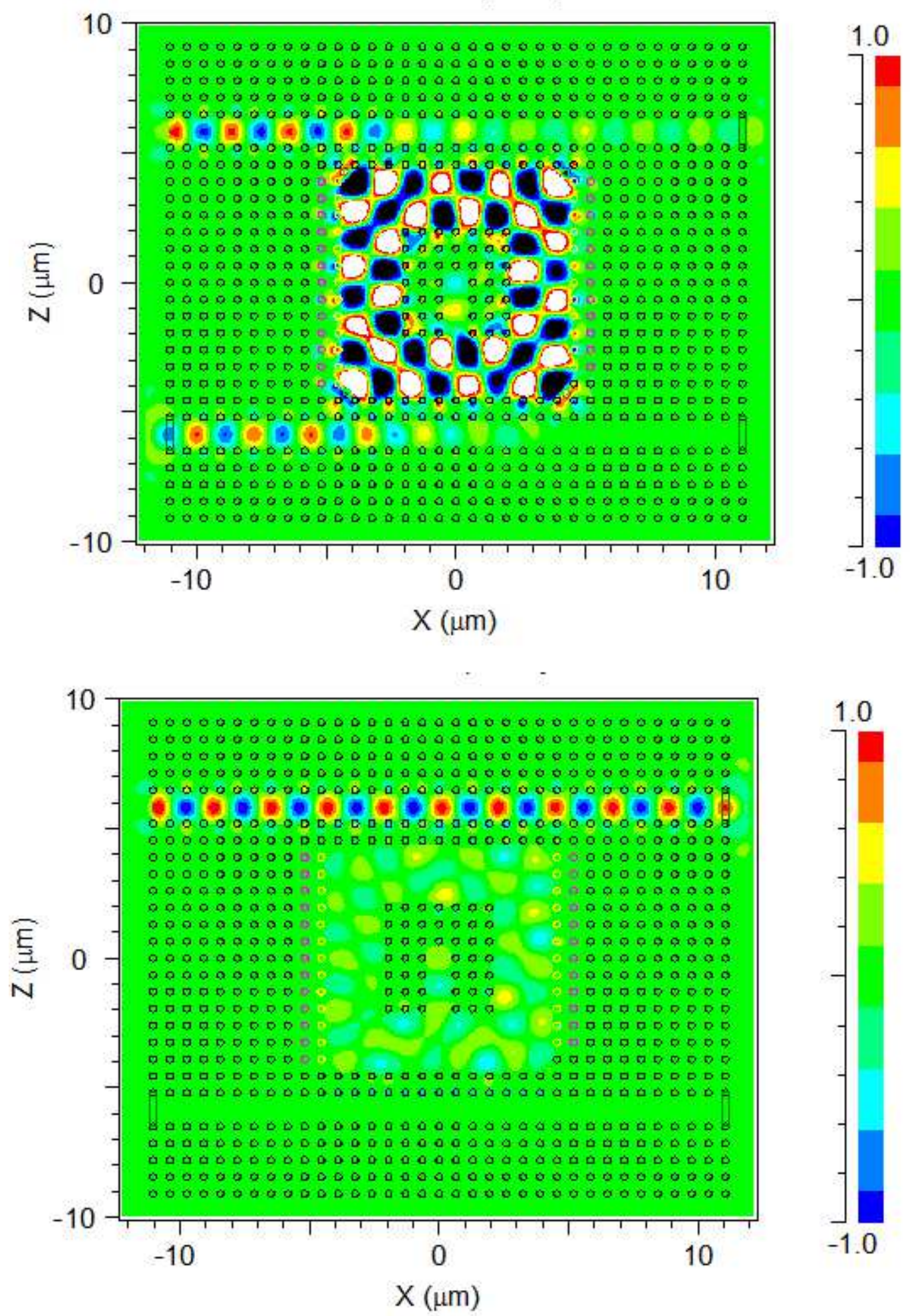

Figure 10

Electric field distribution of the proposed Add Drop filter at (a) ON resonance (1636.2 nm) and (b) OFF resonance $(1633 \mathrm{~nm})$ 


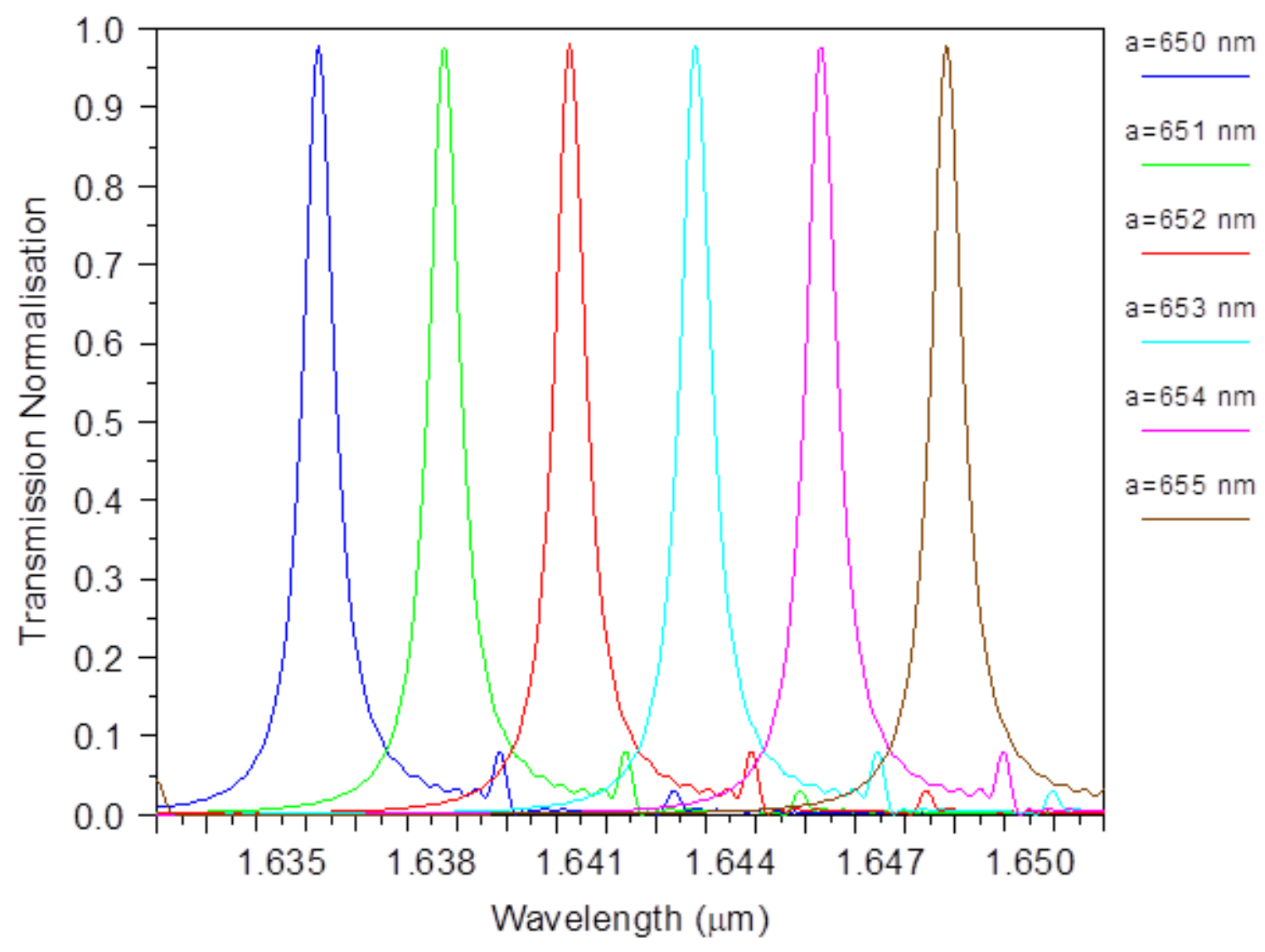

Figure 11

Output spectrum for different lattice constant

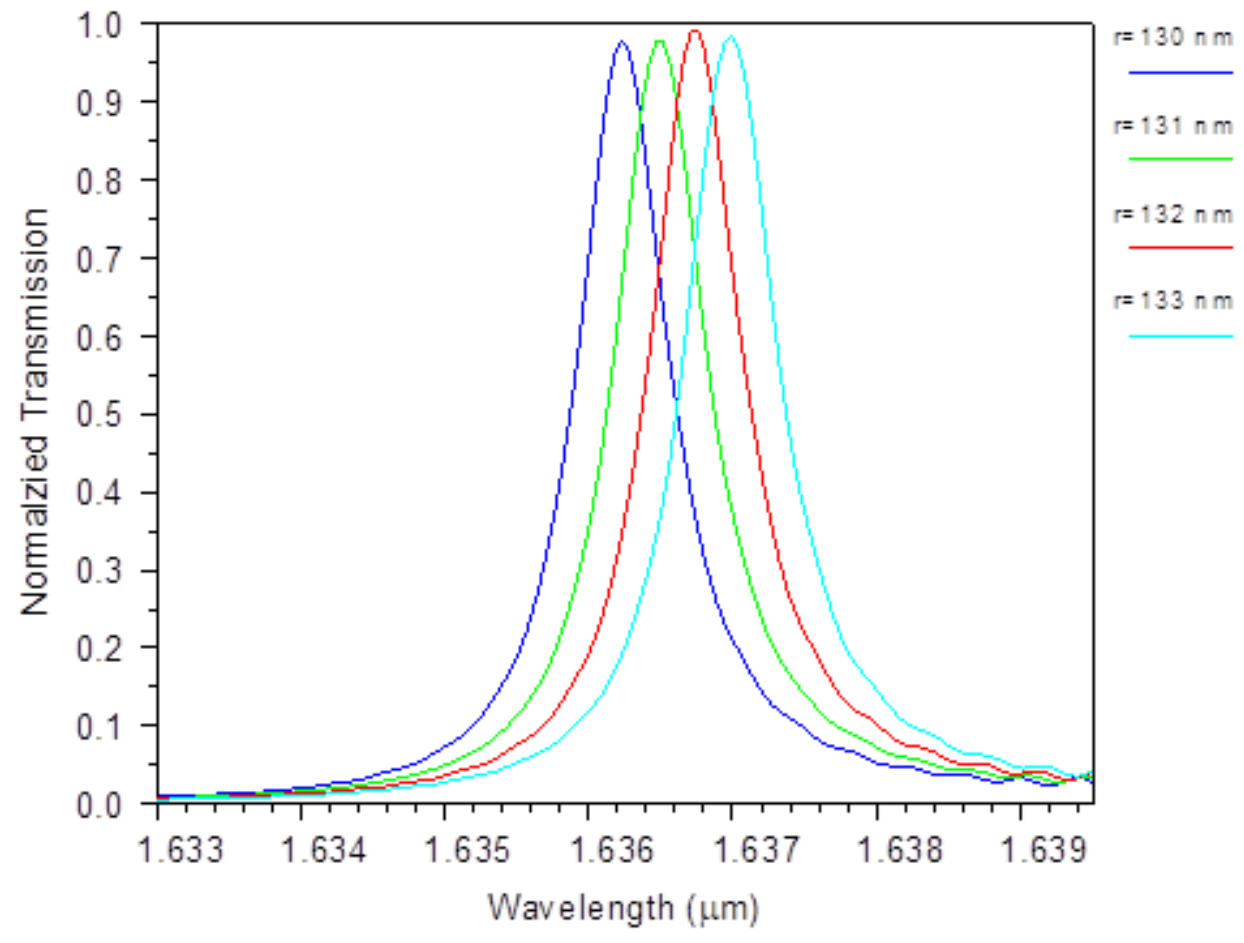

Figure 12 


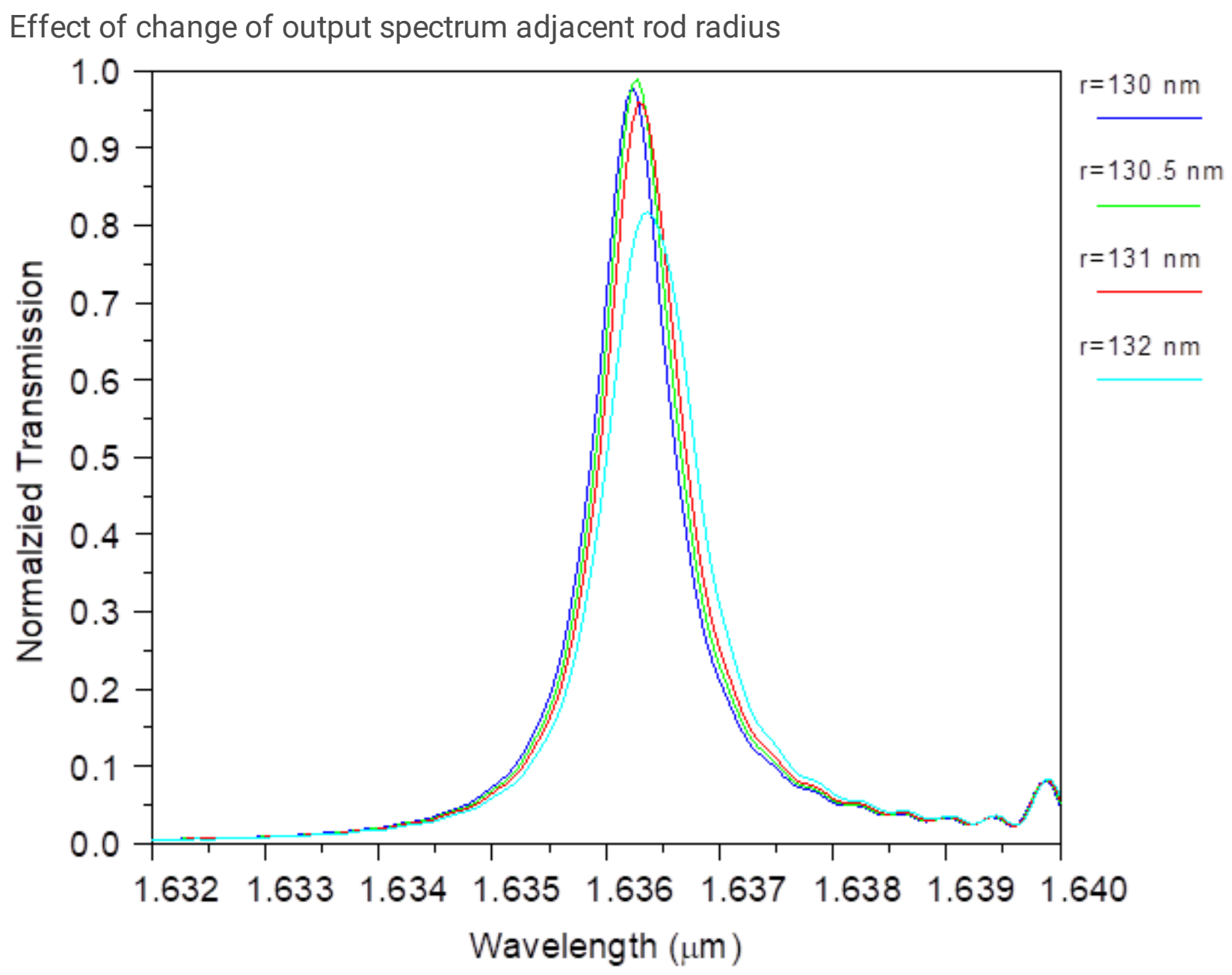

Figure 13

Output spectrum for different scattered rod radius 


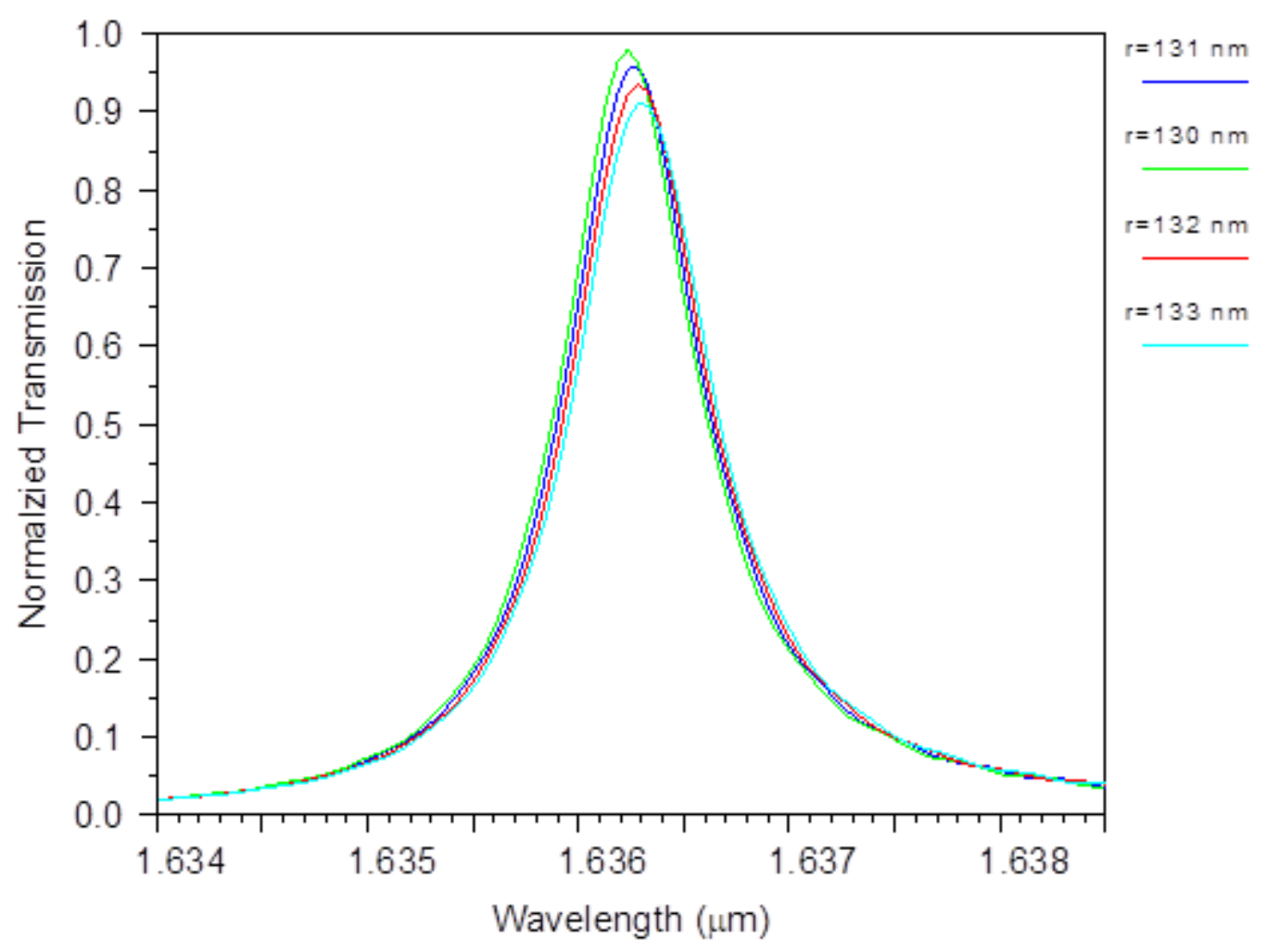

Figure 14

Output spectrum for different coupling rod radius

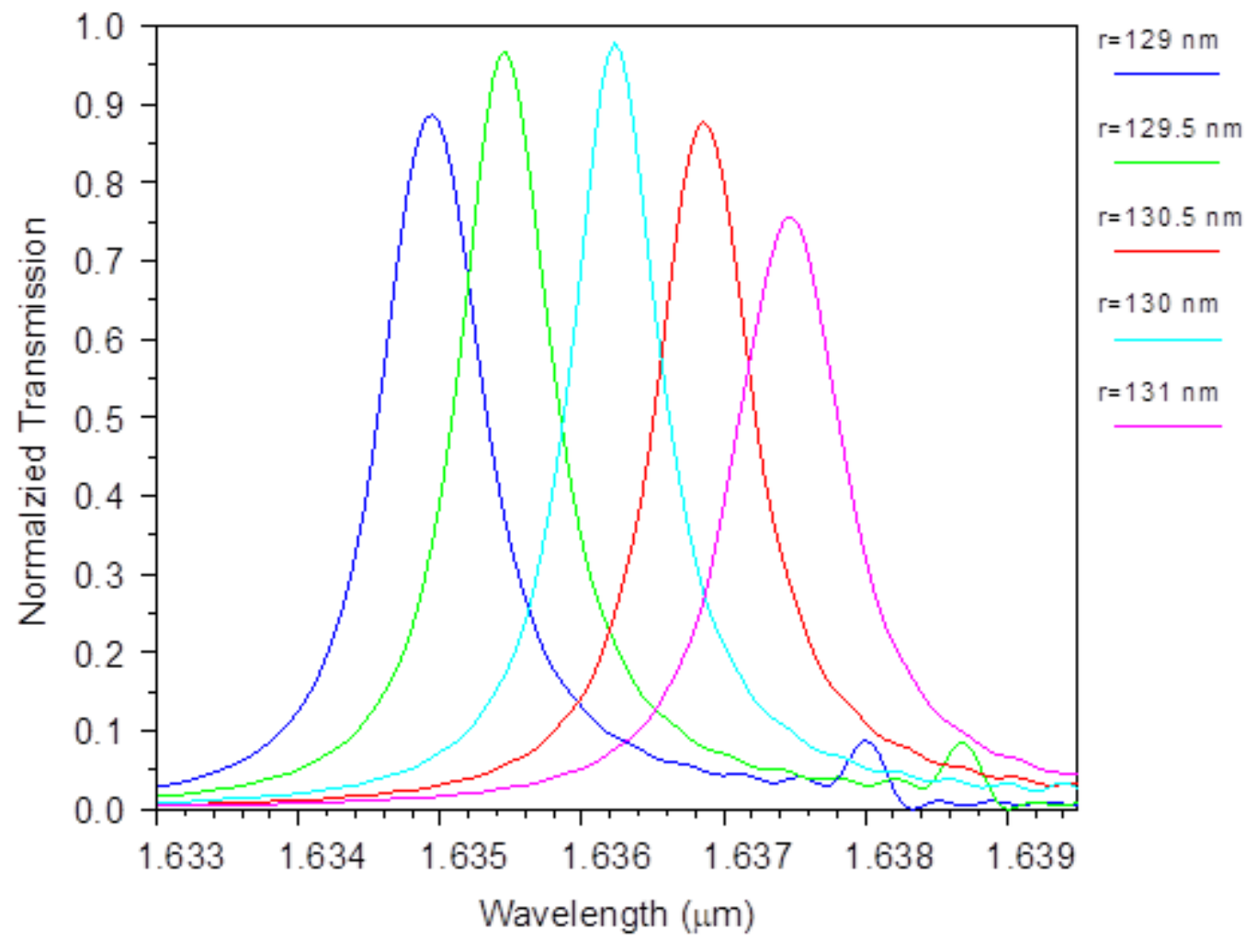

Figure 15

Output spectrum for different coupling rod radius 


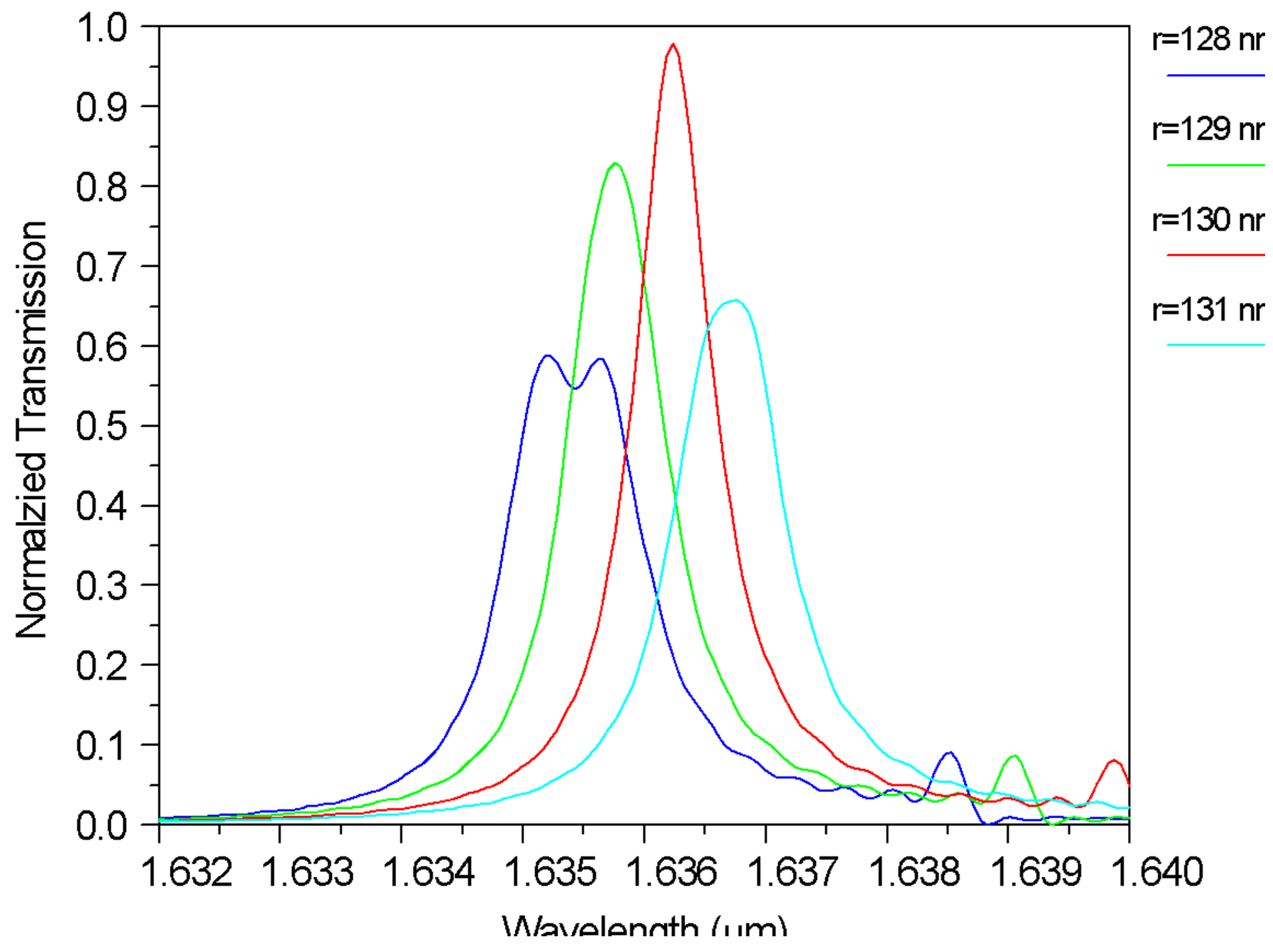

Figure 16

Output spectrum for different inner quasi ring rod radius 


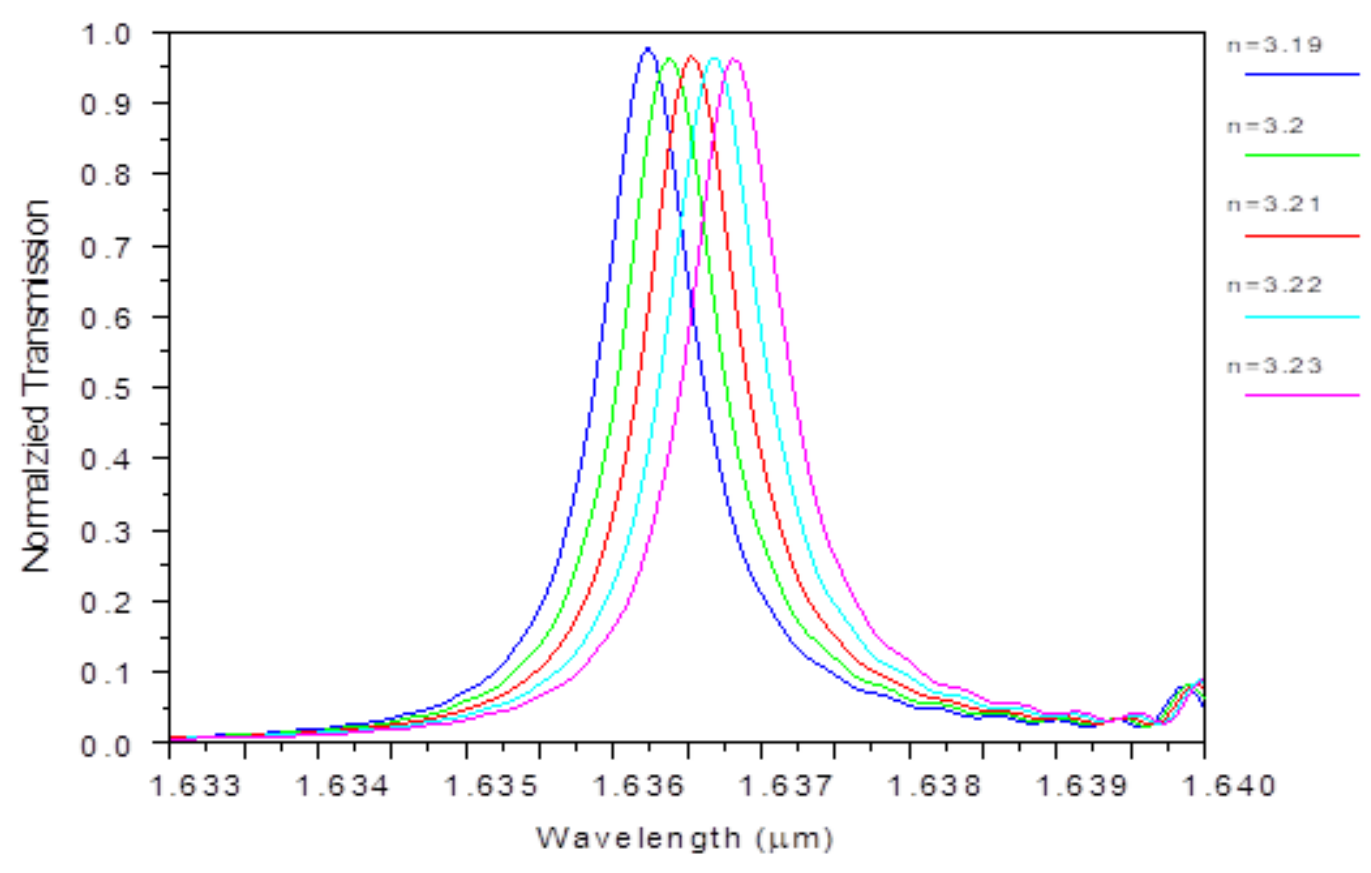

Figure 17

Output spectra of our proposed design for different values of refractive index of adjacent rods

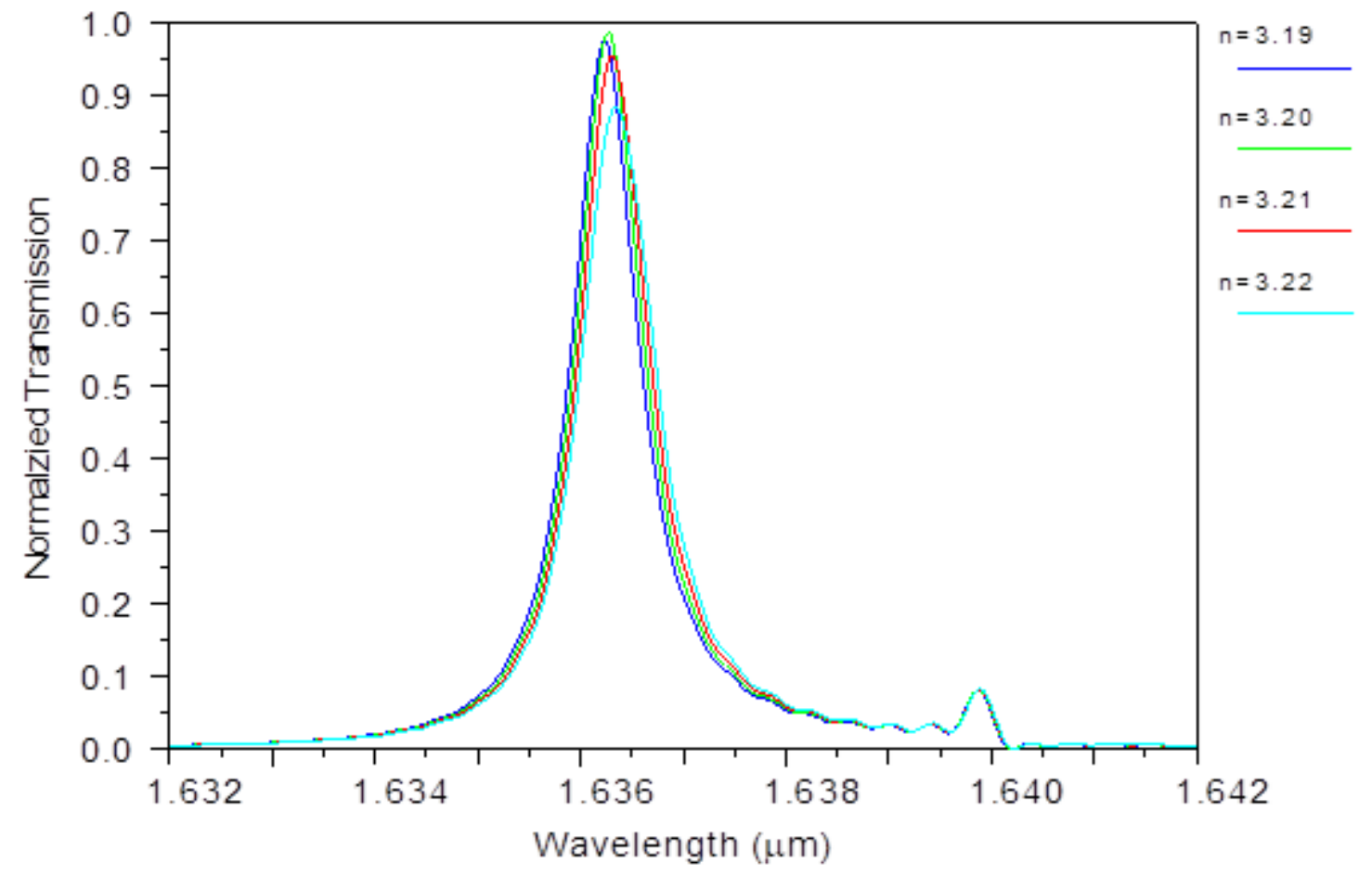

Figure 18

Output spectra of our proposed design for different values of refractive index of corner rods 


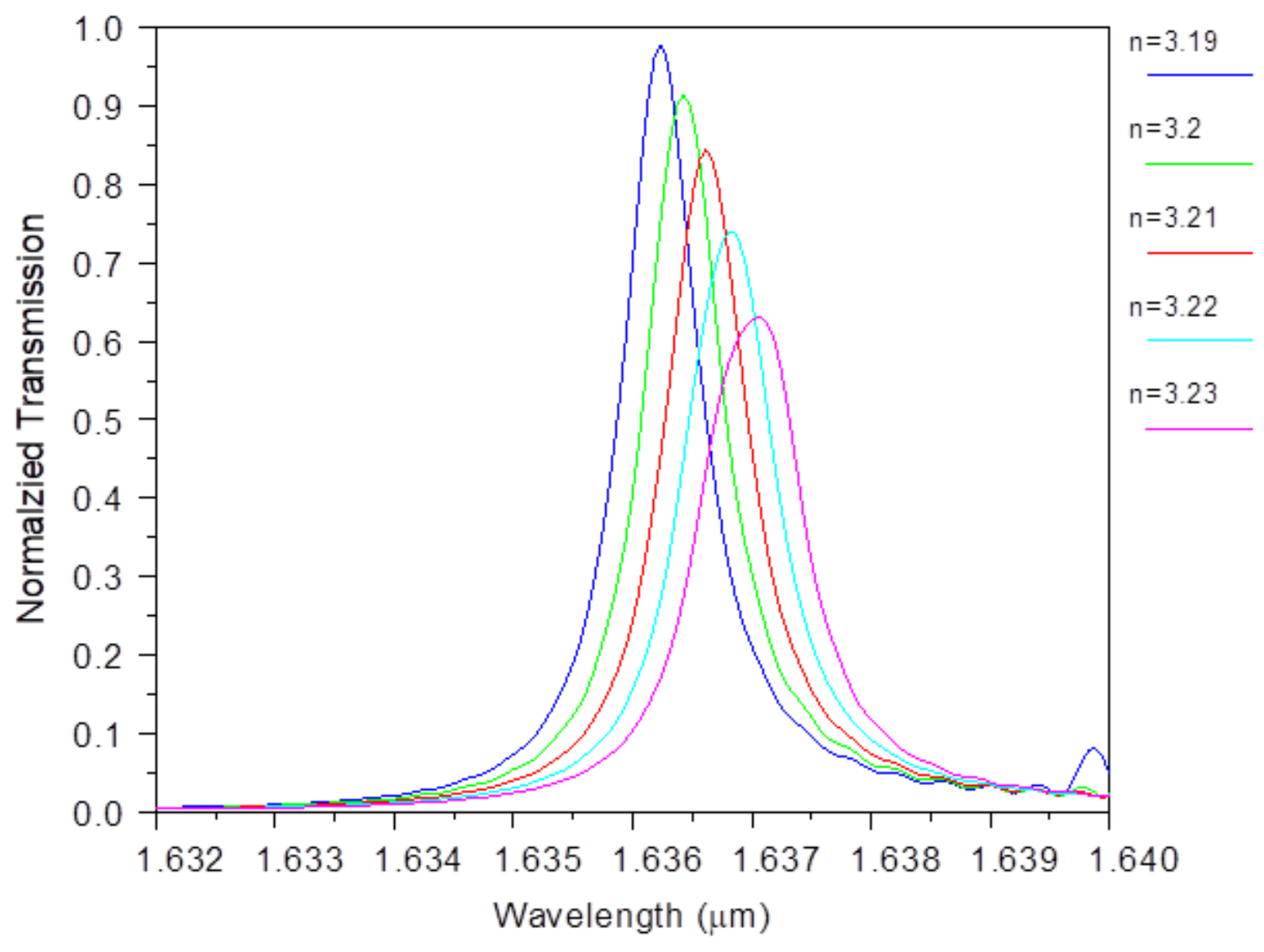

Figure 19

Output spectra of our proposed design for different values of refractive index of coupling rods 


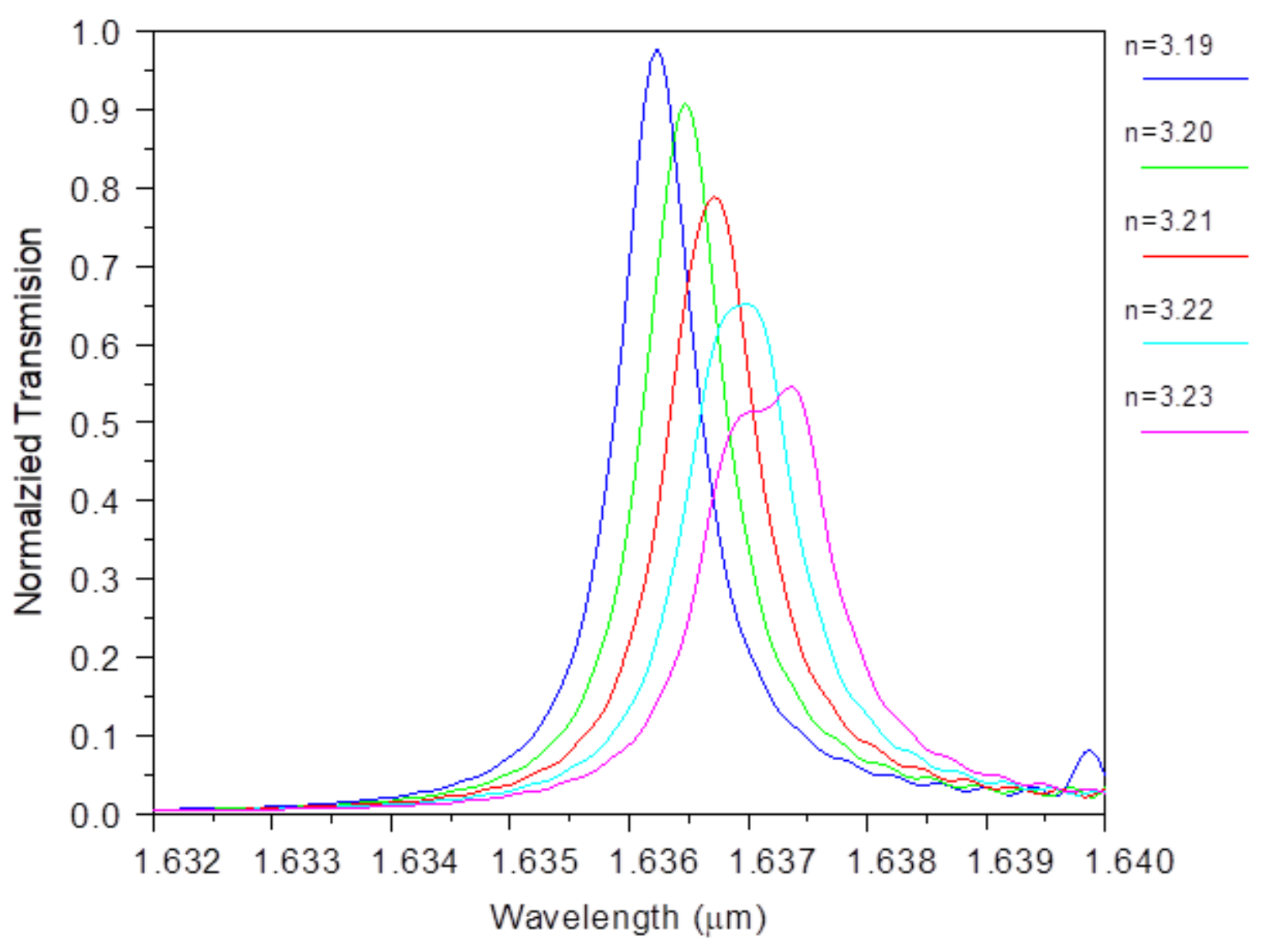

Figure 20

Output spectra of our proposed design for different values of refractive index of inner rods 


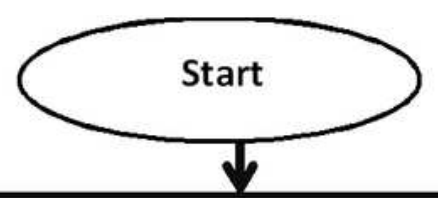

Study the PBG response with PWE for different structural parameters Before and after defects
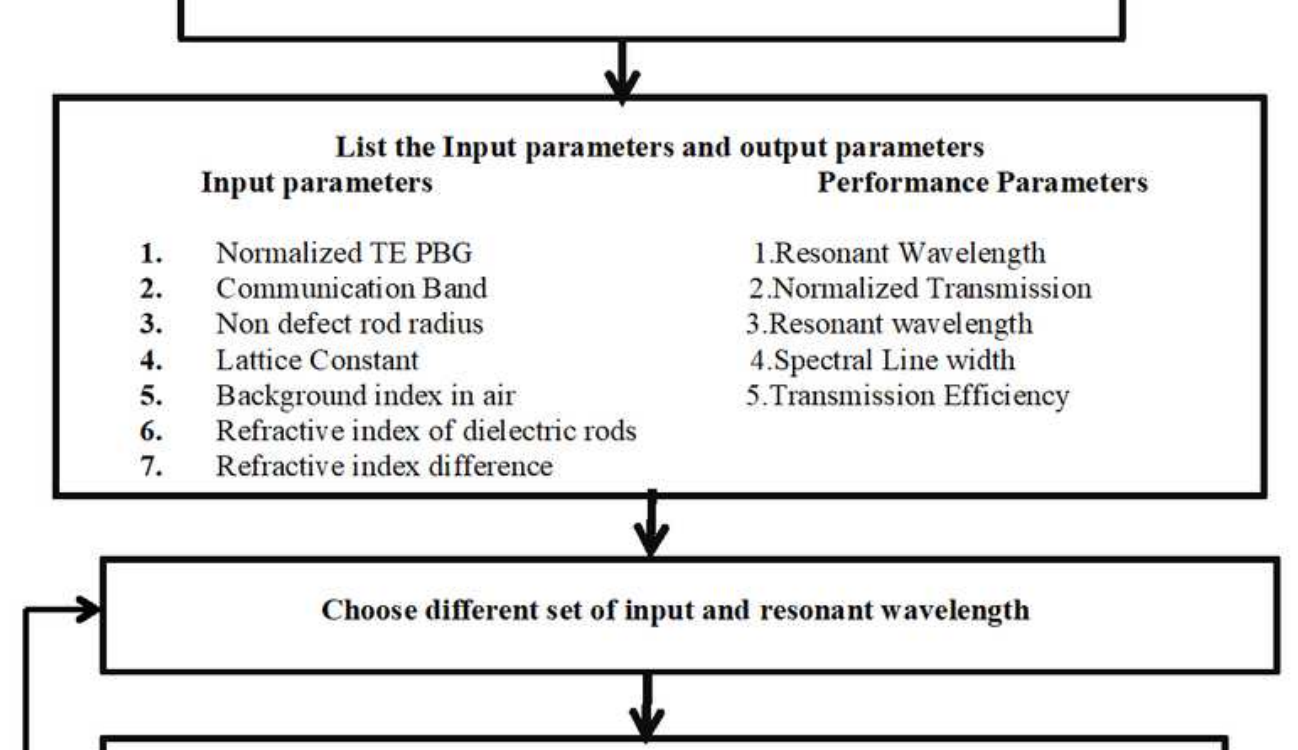

Calculate the error between the expected wavelength and resonant wavelength

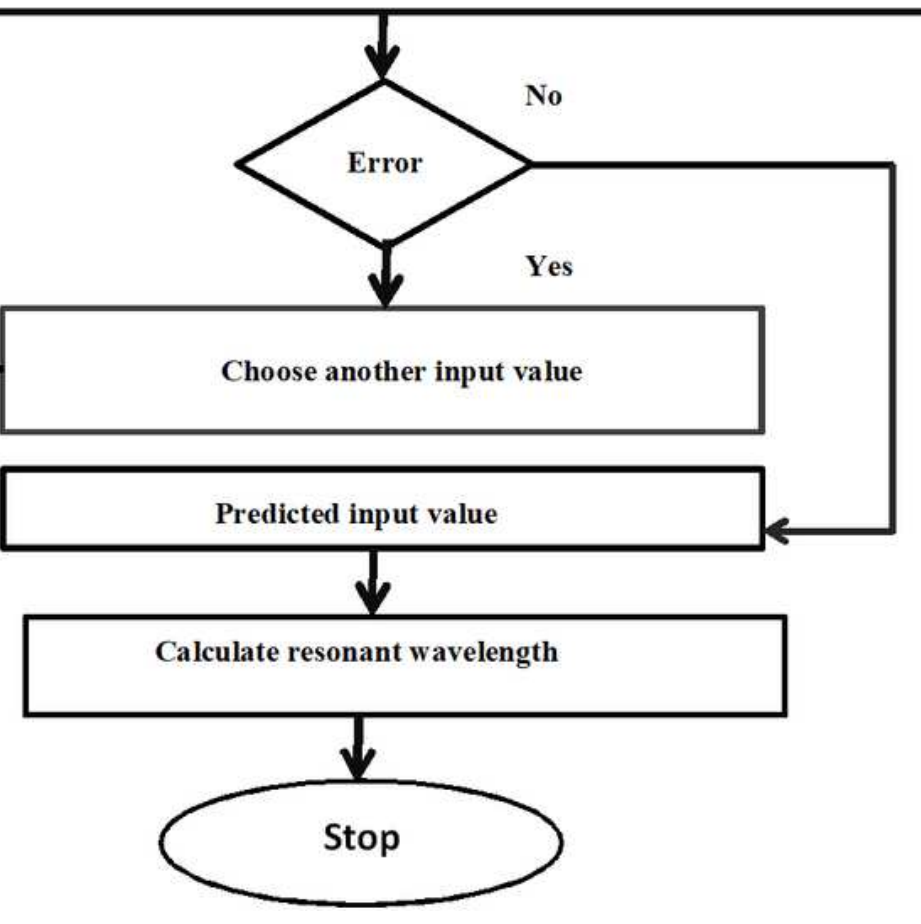

Figure 21

Flowchart of Photonics parameter optimization 